\title{
A Comprehensive Review on Equine Influenza Virus: Etiology, Epidemiology, Pathobiology, Advances in Developing Diagnostics, Vaccines, and Control Strategies
}

\author{
Raj K. Singh ${ }^{1}$, Kuldeep Dhama ${ }^{2 \star}$, Kumaragurubaran Karthik ${ }^{3}$, Rekha Khandia ${ }^{4}$, \\ Ashok Munjal ${ }^{4}$, Sandip K. Khurana ${ }^{5}$, Sandip Chakraborty ${ }^{6}$, Yashpal S. Malik ${ }^{7}$, \\ Nitin Virmani ${ }^{5}$, Rajendra Singh ${ }^{2}$, Bhupendra N. Tripathi ${ }^{5}$, Muhammad Munir ${ }^{8}$ and \\ Johannes $H$. van der Kolk ${ }^{9 *}$
}

OPEN ACCESS

Edited by:

Akio Adachi,

Kansai Medical University, Japan

Reviewed by:

Luis Carlos Villamil-Jiménez, Independent Researcher, Columbia

Eric Claassen

VU University Amsterdam,

Netherlands

Kevin L. Legge

University of lowa, United States

*Correspondence:

Kuldeep Dhama

kdhama@rediffmail.com

Johannes H. van der Kolk

johannes.vanderkolk@

vetsuisse.unibe.ch

Specialty section:

This article was submitted to

Virology,

a section of the journal

Frontiers in Microbiology

Received: 07 March 2018

Accepted: 31 July 2018

Published: 06 September 2018

Citation:

Singh RK, Dhama K, Karthik K, Khandia R, Munjal A, Khurana SK, Chakraborty S, Malik YS, Virmani N, Singh R, Tripathi BN, Munir M and van der Kolk JH (2018) A Comprehensive Review on Equine Influenza Virus: Etiology, Epidemiology, Pathobiology, Advances in Developing Diagnostics, Vaccines, and Control Strategies.

Front. Microbiol. 9:1941.

doi: 10.3389/fmicb.2018.01941
${ }^{1}$ ICAR-Indian Veterinary Research Institute, Bareilly, India, ${ }^{2}$ Division of Pathology, ICAR-Indian Veterinary Research Institute, Bareilly, India, ${ }^{3}$ Central University Laboratory, Tamil Nadu Veterinary and Animal Sciences University, Chennai, India,

${ }^{4}$ Department of Biochemistry and Genetics, Barkatullah University, Bhopal, India, ${ }^{5}$ National Research Centre on Equines, Hisar, India, ${ }^{6}$ Department of Veterinary Microbiology, College of Veterinary Sciences and Animal Husbandry, West Tripura, India, ${ }^{7}$ Division of Biological Standardization, ICAR-Indian Veterinary Research Institute, Bareilly, India, ${ }^{8}$ Division of Biomedical and Life Sciences, Lancaster University, Lancaster, United Kingdom, ${ }^{9}$ Division of Clinical Veterinary Medicine, Swiss Institute for Equine Medicine (ISME), Vetsuisse Faculty, University of Bern and Agroscope, Bern, Switzerland

Among all the emerging and re-emerging animal diseases, influenza group is the prototype member associated with severe respiratory infections in wide host species. Wherein, Equine influenza (El) is the main cause of respiratory illness in equines across globe and is caused by equine influenza A virus (EIV-A) which has impacted the equine industry internationally due to high morbidity and marginal morality. The virus transmits easily by direct contact and inhalation making its spread global and leaving only limited areas untouched. Hitherto reports confirm that this virus crosses the species barriers and found to affect canines and few other animal species (cat and camel). EIV is continuously evolving with changes at the amino acid level wreaking the control program a tedious task. Until now, no natural El origin infections have been reported explicitly in humans. Recent advances in the diagnostics have led to efficient surveillance and rapid detection of EIV infections at the onset of outbreaks. Incessant surveillance programs will aid in opting a better control strategy for this virus by updating the circulating vaccine strains. Recurrent vaccination failures against this virus due to antigenic drift and shift have been disappointing, however better understanding of the virus pathogenesis would make it easier to design effective vaccines predominantly targeting the conserved epitopes (HA glycoprotein). Additionally, the cold adapted and canarypox vectored vaccines are proving effective in ceasing the severity of disease. Furthermore, better understanding of its genetics and molecular biology will help in estimating the rate of evolution and occurrence of pandemics in future. Here, we highlight the advances occurred in understanding the etiology, epidemiology and pathobiology of EIV and a special focus is on designing and developing effective diagnostics, vaccines and control strategies for mitigating the emerging menace by EIV.

Keywords: equine, influenza virus, epidemiology, pathogenesis, diagnosis, vaccine, prevention, control 


\section{INTRODUCTION}

Equine influenza (EI) is an extremely contagious disease of horses (including wild horses), which is caused by Influenza A viruses. These viruses are known for high rates of transmission in a wide variety of animal species. Equine influenza virus (EIV), the causative agent of EI, is considered to be one of the most important viral respiratory pathogens of equines. The disease is characterized by flu-like symptoms affecting predominantly the respiratory tract (Wilson, 1993; Slater and Hannant, 2000; van Maanen and Cullinane, 2002; Newton and Mumford, 2005; Cullinane et al., 2006; Landolt et al., 2007; OIE, 2008; Stack et al., 2013; Kapoor and Dhama, 2014; Yin et al., 2014). The presence of influenza infections has been suggested in horses since the time of Hippocrates and Absyrtus, the latter being a Greek veterinarian, described a disease resembling influenza in $412 \mathrm{BC}$ and 433 $\mathrm{AD}$, respectively. In 1872, an outbreak of influenza occurred throughout the North America and affected large population of horses resulting in crippled transportation of goods, unloading of ships and stoppage of almost all essential services (Law, 1874). In India, one of the largest EI outbreak occurred in 1987 affecting more than 27,000 equines and causing death of several hundred (Uppal et al., 1989). In Australia during 2007, an EI outbreak infected $\sim 10,000$ equines despite keeping strict preventive and control measures. The disease was restricted after great efforts at the colossal cost of about one billion Australian dollars (Cowled et al., 2009).

Equine influenza is mainly caused by two subtypes of influenza A viruses namely H7N7 (first isolated in the year 1956) and H3N8 (first isolated in the year 1963; Sovinova et al., 1958; Waddel et al., 1963). Previously, H7N7 was considered as the major cause of epidemics whereas latter $\mathrm{H} 3 \mathrm{~N} 8$ strain is mainly responsible for outbreaks across the globe (Mathew et al., 2010; Bryant et al., 2011; Alves Beuttemmüller et al., 2016). Genetic analysis has revealed close relatedness of $\mathrm{H} 3 \mathrm{~N} 8$ strains of EI with avian influenza virus (AIV), which may indicate co-existence of influenza viruses in aves and equines (Cullinane and Newton, 2013). Notably, EIV has been seen to infect unusual host, dogs (Kirkland et al., 2010; Wang et al., 2017). Although, before 2004, canines were considered resistant to influenza virus infection, the recent epidemic of influenza in canines came as a surprise (Gibbs and Anderson, 2010). Interspecies transmission of the virus has been reported in racing greyhounds in the USA where the isolated virus showed close relatedness to $\mathrm{H} 3 \mathrm{~N} 8$ virus (Crawford et al., 2005). Further studies confirmed that though this virus was earlier considered to be confined to the equine host exclusively, it has been demonstrated in canines (Crawford et al., 2005; Gibbs and Anderson, 2010; Hayward et al., 2010; Landolt, 2014), zebras, camels (Yondon et al., 2014), and humans (Larson et al., 2015).

The evolution (intra-host) of EIV has been recorded in naive horses and during field outbreaks (Murcia et al., 2010; Hughes et al., 2012). Antigenic drift (caused by point mutation) has resulted in emergence of "European" and "American" lineages of H3N8 (Wilson, 1993; Daly et al., 1996, 2004; Oxburgh and Klingeborn, 1999; Purzycka et al., 2004; Cullinane and Newton, 2013). As of now, human infections with EIV have not been reported, and only serological evidences exists without virus isolation from specimens. Although, zoonotic implications of EIV have not yet been fully elucidated, nevertheless, the virus can pose a threat to laboratory personnel (Alexander and Brown, 2000; OIE, 2008). Since detection of EIV in dogs, it is presumed that this virus can re-assort (H3N8) with human influenza virus and might lead to the emergence of novel strains ( $\mathrm{Na}$ et al., 2016).

Although vaccination is the most useful prophylactic strategy; continuous genetic evolution of the virus demands genetic characterization of currently circulating EIVs for the selection of a candidate vaccine strain. As vaccine failures occur in several parts of the world there is need for a better vaccine to completely eradicate equine influenza (Kinsley et al., 2016). Hence, understanding of the molecular mechanisms involved with its cross-species transmission is of prime importance to devise any prophylactic and control strategy (Holland, 2003; Smyth, 2007; Joseph et al., 2017).

The present review comprehensively describes EIV and the disease it causes, epidemiology, transmission, pathogenesis and pathology, advances in diagnosis, vaccine development and appropriate prevention, and control strategies to be adapted.

\section{ETIOLOGY}

Based on the matrix and nucleoprotein genes of influenza viruses, they have been classified as type A, B, C, and D. Type A viruses mainly infect animals and humans while type $B$ and $C$ viruses infect only humans. A close relative of Type $C$ virus, Type D was first reported in the year 2011 from swine and later identified from cattle, sheep, and goats (Ferguson et al., 2016). Serosurveys showed that type D antibodies were found in humans and equines also (Nedland et al., 2018). AIV is considered as an ancestor to all other influenza viruses of mammalian and nonmammalian species. H7N7 and H3N8, the major subtypes of EIV, were previously referred as equine 1 and 2 viruses, respectively (Daly et al., 2011; Chambers, 2014; Sreenivasan et al., 2018). EIV is a segmented RNA virus with $80-120 \mathrm{~nm}$ in diameter and is classified under the family Orthomyxoviridae belonging to the genus Influenza A (Timoney, 1996). Influenza A viruses possess eight single segmented negative sense RNA strands and are sub-typed based on the two surface glycoproteins that make $45 \%$ of the mass of this virus, namely hemagglutinin (HA) and neuraminidase (NA) (Webby et al., 2007; Cullinane and Newton, 2013; Lewis et al., 2014). The shape of EIV particle is greatly determined by segment 7 (Elton et al., 2013). The segmented genome of EIV encodes at least 10 classical proteins. The proteins that are encoded by the segmented genome are: structural proteins which are termed as HA, NA, nucleoprotein (NP), matrix proteins (M1 and M2), three polymerase proteins (PB1, PB2, and PA), one nuclear export protein (NEP) and a nonstructural protein named as NS1. As a result of complementary sequences and frame shift other minor yet important proteins are also expressed. HA and NA glycoproteins are termed as spikes as these projects outside the envelope, essential for viral entry and release (Timoney, 1996; Easterday et al., 1997; Figure 1). 


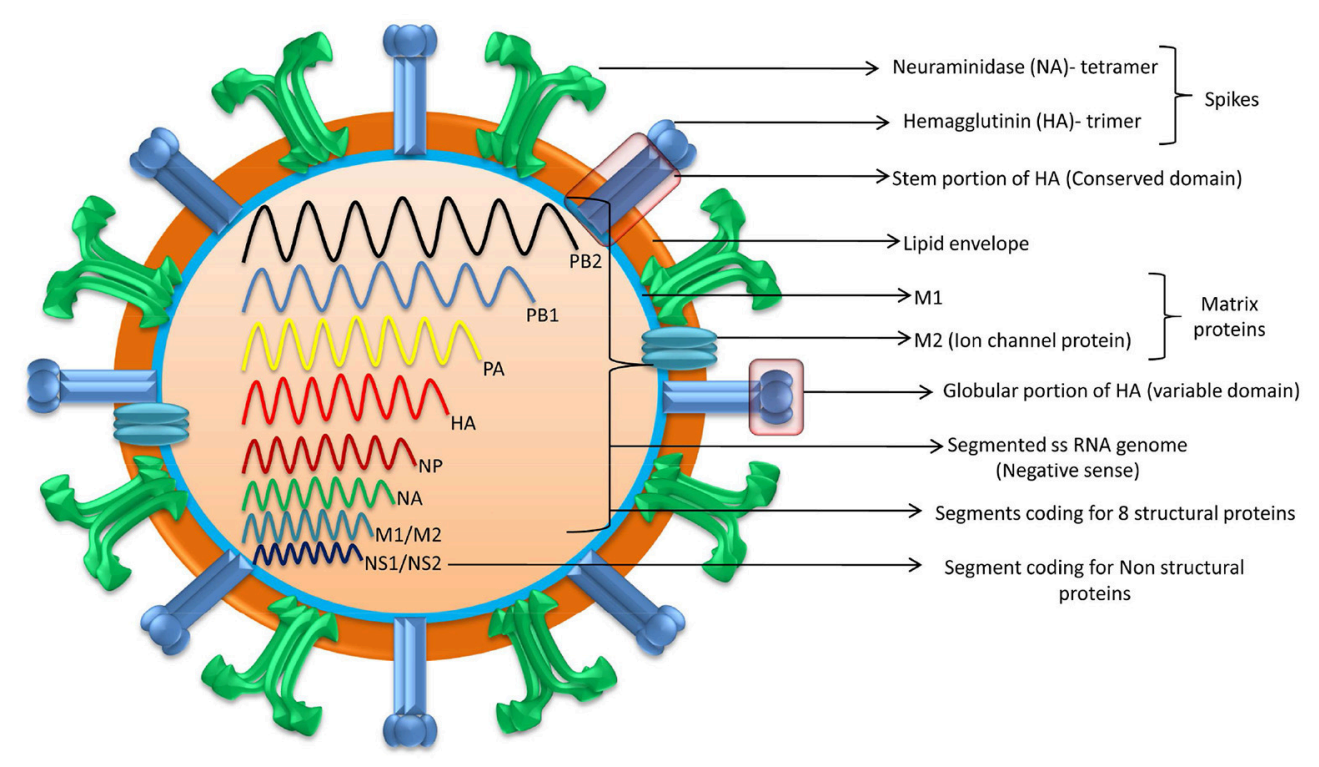

FIGURE 1 | Structure of Equine Influenza Virus. EIV is a segmented RNA virus possessing eight (single) segmented negative sense RNA strands. Segmented genome encodes eight structural proteins and at least two non-structural proteins.

Complete transcription of segment 8 leads to expression of NS1 while pre-mature splicing leads to expression of NEP (Lamb and Lai, 1980). Earlier NEP was thought to be a non-structural protein and termed as NS2 and later studies indicated that this protein was found within virion and have interaction with $M$ protein (Paterson and Fodor, 2012). NEP is essential for the release of viral ribonucleoprotein from the host nucleus. Viral RNA segments 2 and 3 codes for PB1 and PA which are the major virulence factors. Further, $\mathrm{PB} 1$ subunit can give rise to three proteins namely, $\mathrm{PB} 1, \mathrm{~PB} 1-\mathrm{F} 2$, and $\mathrm{PB} 1-\mathrm{N} 40 .+1$ reading frame of PB1 segment codes for the PB1-F2 (on average 90 amino acid length) which has apoptosis induction function (Krumbholz et al., 2011). N40 is another version of PB1 where there is truncation in the $\mathrm{N}$ terminal region of PB1 (Wise et al., 2009). $\mathrm{PA}-\mathrm{X}$ is a recently described protein which is the outcome of ribosomal frame shifting of segment 3 mRNA during translation (Jagger et al., 2012). It is noteworthy that the PA-X protein of the virus causes suppression of host gene expression (Feng et al., 2016; Oishi et al., 2018).

NS1, a homodimer protein (215-237 amino acids), is an important virulence factor of influenza virus as it modulates several viral and host cellular mechanisms during influenza replication cycle. There are two functional domains in case of NS1 protein named as RNA binding domain ( $\mathrm{N}$ terminal end) and effector domain (C terminal end; Chien et al., 2004). NS1 possess different epitopes hence having multifunctional activities. NS1 protein plays a crucial role in influenza infection by antagonizing type I interferon of host and reducing IFN $\beta$ production (Hale et al., 2008). On the basis of nucleotide homology, NS segment of influenza A virus are divided into $\mathrm{A}$ and $\mathrm{B}$ allele. All mammalian influenza isolates except equine origin H3N8 belong to allele A (Guo et al., 1992).
HA and NA proteins are the important surface antigens in EIC and antibodies generated against them provide resistance to infection (Landolt, 2014). Neutralizing antibodies are formed against HA that can block virus entry and antigenic drift at this molecule can lead to vaccine failure (Yates and Mumford, 2000). Similarly, protective antibodies against NA aggregates the virus on host cell surface and hinders the virus release from the cells (Sylte and Suarez, 2009). Heterotypic immunity is provided at minimum level by humoral responses; whereas cross-reactive response (mediated by cytotoxic $\mathrm{T}$ lymphocytes) is observed between the viral subtypes, true for all the subtypes of type A viruses (Hemann et al., 2013; McKinstry et al., 2013; Landolt, 2014). Subtle changes in the constitution of amino acid may result in immune escape due to different antigenicity (Park et al., 2009) and recently, it has been revealed that there are nine substitutions in the sequences of HA of Brazilian EIV isolates in comparison to the vaccine strain (Florida Clade 1; Favaro et al., 2018).

A detailed investigation of 1989 UK outbreak using reverse genetics and site-directed mutagenesis determined the role of amino acid substitutions within HA glycoprotein (Woodward et al., 2015), and mutations at positions 159, 189, and 227 were found to be associated with altered antigenicity, as revealed by $\mathrm{HI}$ assays. The antigenic site $\mathrm{B}$ was suggested to be the major antigenic site (Daly et al., 1996) and K189 in it is also important for differentiation in Eurasian sub-lineage (Lewis et al., 2011). K189 residue retains a very important role in pertaining antigenicity and switching between uncharged, acidic and basic amino acid is responsible for differed antigenic properties (Ye et al., 2013). The same position has been noticed important for altered antigenic phenotype in H3N2 viruses (Koel et al., 2013), and the same mutation has been found culprit for human vaccine breakdown in Iran during 2005-2006 (Moattari et al., 2010). 


\section{EIV SUBTYPES, LINEAGES, AND SUBLINEAGES}

EIV has two recognized subtypes namely H7N7 (subtype 1) and $\mathrm{H} 3 \mathrm{~N} 8$ (subtype 2), of which $\mathrm{H} 3 \mathrm{~N} 8$ predominantly circulates in equines. H3N8 subtype was isolated for the first time in 1963 from the horses showing the symptoms of flu in USA, designated as A/eq/Miami/63 and is considered as prototype virus (Waddel et al., 1963). Earlier, it was hypothesized that H3N8 subtype viruses evolved as a single lineage (Kawaoka et al., 1989). Based on the sequence analysis of the HA gene, the H3N8 EIV shows two genetic and antigenic variants (Figure 2) evolving after 1980s namely Eurasian and American lineages (Daly et al., 1996). Subsequently, American lineage evolved into three sublineages namely Argentinian, Kentucky, and Florida (Lai et al., 2001). Further, evolution of the Florida sublineage has resulted in the emergence of two groups of viruses with divergent HA sequences (Figure 2) which are provisionally referred to as Florida sublineage clades 1 and 2 viruses (Bryant et al., 2011). Currently, Clade 1 and Clade 2 lineage viruses have been circulating across the globe and leading to outbreaks. Clade 1 viruses have been circulating more in American continent while Clade 2 viruses have been incriminated for most of the outbreaks in Europe and Asia. Both clades have been reported in major outbreaks throughout the world (Bryant et al., 2009). However, outbreaks due to both of them keep on occurring across the geographic barriers. Florida Clade 1 viruses have been responsible for major outbreaks in Japan and Australia in 2007-08 (Bryant et al., 2009) while Clade 2 viruses caused huge outbreaks in China, India, and Mongolia (Virmani et al., 2010a). A/eq/South Africa/04/2003-like or A/eq/Ohio/2003-like viruses are representative of clade 1, A/eq/Richmond/1/2007like viruses represents clade 2 and Newmarket/2/93 represents Eurasian lineage (Laabassi, 2016). Since 2013, some of the isolates from Europe have been consistently showing two amino acid changes viz. A144V and I179V (Figure 2) in the antigenic region and have been referred two as subgroups in Clade 2 lineage. The changes are in the antigenic site; however, they have not affected the HI assay using the postinfection Ferret antisera (Woodward et al., 2014; Rash et al., 2017).

\section{EPIDEMIOLOGY AND EVOLUTION}

Since 1956, when marked widespread respiratory epidemic disease occurred in equines due to EIV, Europe and North America are the most endemic regions for EI, and almost all nations in the world have witnessed outbreaks caused by EIV except few small island countries like New Zealand and Iceland. Currently, EI is prevalent worldwide viz. Europe, Canada, USA, Turkey, Scandinavia, and South America (Sovinova et al., 1958; Waddel et al., 1963; Gerber, 1970; Uppal et al., 1987; Wood and Mumford, 1992; Wilson, 1993; Timoney, 1996; van Maanen and Cullinane, 2002; Radostits et al., 2003; Purzycka et al., 2004; Newton and Mumford, 2005; Mathew et al., 2006; Landolt et al., 2007; Smyth, 2007; Foord et al., 2009; Sajid et al., 2013;
Gahan et al., 2017). Increase in equine traffic has led to the spread of EIV to other countries including South Africa in 2003. Australia has reported the disease for the first time in 2007 and the disease was re-introduced to Japan and South Africa (Ito et al., 2008; OIE, 2008; Yamanaka et al., 2008a; Foord et al., 2009; Alves Beuttemmüller et al., 2016). Improper quarantine of sub-clinically affected animals, which were not sufficiently vaccinated, led to spread of this virus to Australia as seen in the Australian outbreak in the year 2007 when about 76,000 horses were found infected (Cullinane and Newton, 2013). During this outbreak, EIV was also noticed in dogs that were in close proximity to horses but without any lateral transmission (dog-todog; Kirkland et al., 2010; Crispe et al., 2011). Similar observation of Transmission of EIV subtype H3N8 to English foxhounds has also been reported during an outbreak in the year 2002 in the United Kingdom (Daly et al., 2008). Most EIV strains isolated recently all over the world originate from the Florida group. Kwasnik et al. (2016) compared available GenBank database of full-length NS sequences of EIV with Florida group. The alignment indicated $1194 \mathrm{~V}$ common in all American lineages and may serve as a discriminator from Eurasian lineages. EIV does not show any seasonal incidences thus can occur at any time of the year (Chambers, 2014; Landolt, 2014). Mortality due to EIV is rare, which can happen in foals devoid of maternally derived antibodies and also in affected horses and donkeys that is devoid of rest. Also, due to the presence of maternally derived antibodies the incidence of this disease is quite low in foals (Landolt, 2014).

Several prototypes of the virus have been isolated in during 1956 to 1989 including influenza A/equine/Prague/1/56 (H7N7), influenza A/equine/Miami/ 1/63 (H3N8), while influenza A/equine/Jilin/1/89 (H3N8), which has emerged by transspecies transmission from birds in China in the year 1989 (Chambers, 1992; Guo et al., 1992). H7N7 was nominated as the prototype EIV and there was no report of isolation of H7N7 after the year 1979 (Webster, 1993). H7N7 has only been reported twice in the Asian continent; first time in Malaysia in the year 1977 and later for the second time in India in the year 1987 based on sero-survey studies (Uppal and Yadav, 1987; Uppal et al., 1987). Disappearance of H7N7 may be explained on the basis of the codon usage concept where it was observed that in this strain possessed strong codon biasness is strong and not guided by mutation pressure or nucleotide composition (Kumar et al., 2016). In the year 1963, H3N8 subtype caused a major epidemic in the USA (Florida), which was later designated as equine subtype 2 (Daly et al., 2004). Evidence suggests that there was a spread of the H3N8 virus from Florida to countries like Australia, Japan as well as China (Murcia et al., 2013; Karamendin et al., 2014). Now, the H3N8 subtype virus mainly circulates throughout the world. South America is considered to be the origin of the spread of $\mathrm{H} 3 \mathrm{~N} 8$ to other countries (Perglione et al., 2016).

Several reports regarding outbreaks and evolution of the virus are documented throughout the world and comprehensive reports from various such studies from different continents are documented in the following section. 


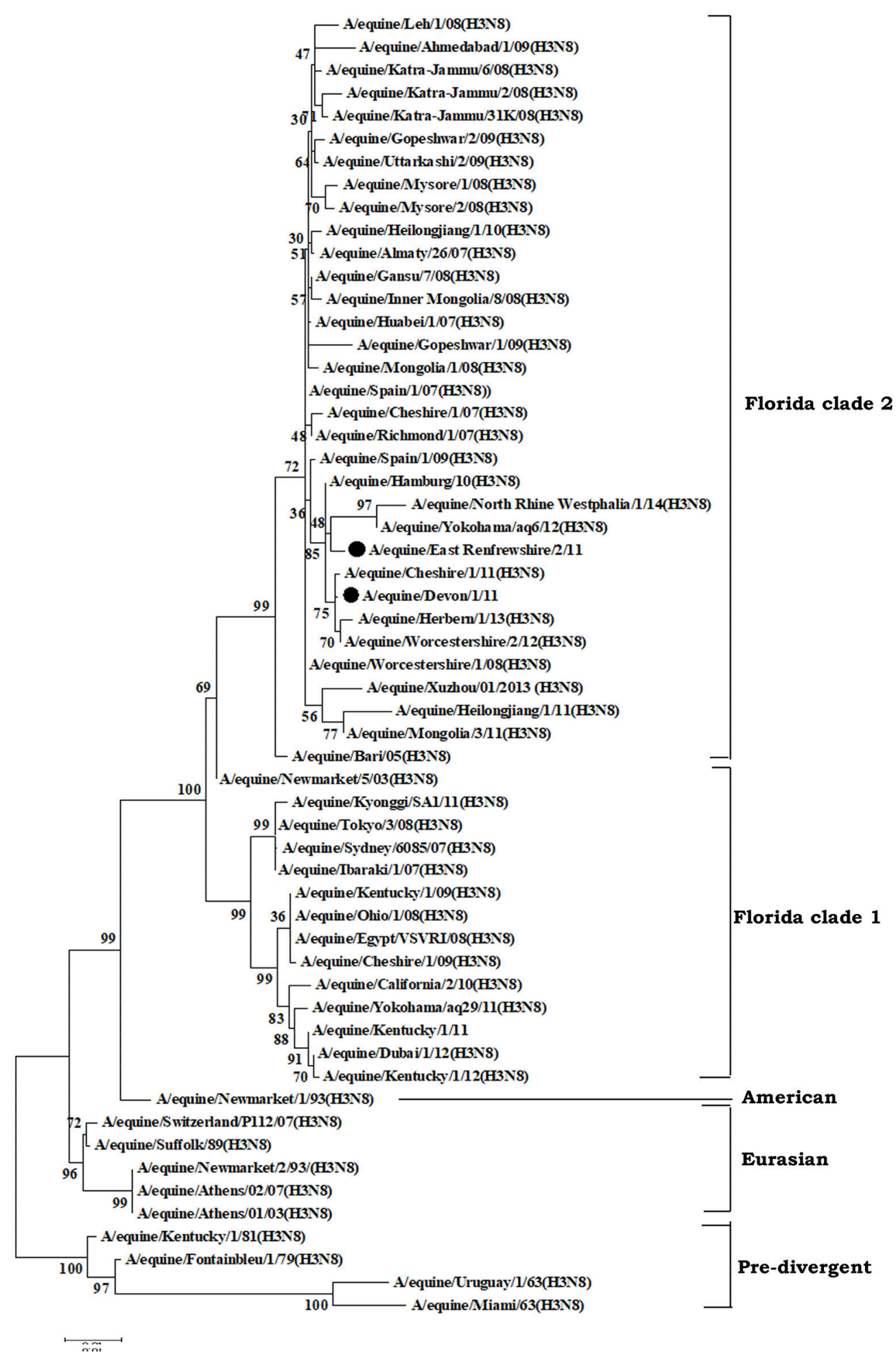

FIGURE 2 | Phylogenetic analysis of hemagglutinin (HA) genes nucleotide sequences from 57 Equine Influenza Viruses (EIVs). The maximum likelihood tree was constructed using stringent T92 $+\mathrm{G}$ algorithm which was identified using the find best DNA/protein model tool available in MEGA 6. The reliability of the trees was assessed by bootstrap with 1,000 replications with cut off at 50 are shown in the tree. The phylogram depicts five major clusters of global ElVs. Phylogenetic group's viz., Florida sub-lineage clade 1, Florida sub-lineage clade 2, American, Eurasian and Pre-divergent, are mentioned by bars on the right. The major mutations (1179V and A144V) observed in the Clade 2 viruses of Florida sublineage in recent isolates have been denoted by solid dots. 


\section{North America}

A/equine/Montana/9564-1/2015 (H3N8) was isolated from an outbreak in USA during 2015 from the unvaccinated equines and sequence analysis showed that the virus was identical to A/equine/Tennessee/29A/2014 (H3N8) based on its polymerase acidic (PA), polymerase basic protein 1 (PB1), hemagglutinin (HA), matrix (M) and nucleoprotein (NP), while analysis of non-structural proteins (NS), neuraminidase (NA), and PB2 showed maximum identity with A/equine/Malaysia/M201/2015 (H3N8). The virus could grow on various primary cells derived from bovine, equine, human, and swine implying that it has the potential to cross species barrier and produces infection (Sreenivasan et al., 2018).

A Canadian study at a racetrack showed $76 \%$ prevalence of EIV (Morley et al., 2000). A surveillance study in Ontario, Canada showed that morbidity rate of EIV was $56.6 \%$ among the equine respiratory outbreaks. H3N8 was also isolated from 15 horses affected during five different outbreaks (Diaz-Mendez et al., 2010).

A recent sero-survey conducted in West Indies among 140 horses and 40 donkey serum samples revealed 49 samples positive for EI antibodies. This was the first report of EIV infection from Leeward Islands of West Indies (Bolfa et al., 2017).

\section{South America}

Gaíva e Silva et al. (2014) observed seropositivity of EIV in $92 \%$ of equines amongst Brazil equine establishments. The high prevalence of antibodies against EIV suggested that the virus circulated extensively among the animals, and statistical analysis indicated that the movement and high aggregation of animals are associated with virus transmission. In the year 2015, EIV outbreak was reported from both the vaccinated and unvaccinated equines in Brazil. Notably, all the 12 isolates recovered during the outbreak were classified as Florida Clade 1 EIV. The reason behind these outbreaks were identified either the use of old vaccine without updation or the use of updated vaccine without proper trail (Favaro et al., 2018).

\section{Europe}

A genetic analysis of HA1 domain of hemagglutinin H3 of EIV isolated during 2005 to 2010 was determined and the genetic evolution of French EIV strains and strains isolated globally was performed (Legrand et al., 2015). The study revealed that EIVs evolved in France during 2005-2010 in a similar manner as other parts of world. Genetic evolution study of all the EIV isolated in France from 1967 to 2015 was studied and it was found that till 2003 American and Eurasian lineages were predominating while the Florida sub-lineage Clade 2 predominated after 2005 (Fougerolle et al., 2017).

Genetic characterization of Italian isolates revealed a close relatedness to American, European, and also the prototype vaccine lineage A/eq/South Africa/4/2003 isolate (Damiani et al., 2008). First incidence of Florida clade 1 virus in Nordic countries was reported in the year 2011 in Sweden which supports the use of both clade 1 and 2 Florida sublineage viruses in the vaccine (Back et al., 2016). HA1 gene of 18 EIV isolated during 20072010 in Ireland was carried out and it was found that all isolates belonged to Florida sublineage hence Expert Surveillance Panel recommended the use of both clades of Florida sublineage in the vaccine (Gildea et al., 2012). Later in 2014, EIV outbreaks were reported in 19 premises of Ireland. Though there was clear vaccination history against EIV which may be due to the nonupdation of vaccines with Clade 2 of the Florida sublineage (Gildea et al., 2018). Phylogenetic analysis of HA and NA gene of Greek EIV isolates recovered during the year 2003-2007 showed that they are related to Eurasian lineage and Florida sublineage clade 2 , respectively. This study suggests that there may be possibility of reassortment (Bountouri et al., 2011). Recently in February 2018 there was report of equine influenza from Scotland and the virus belonged to Florida clade 1 sublineage and this sublineage has not been reported in UK after 2009 (Whitlock et al., 2018).

\section{Africa}

African countries also reported this virus. A study in Nigerian horses showed the presence of $\mathrm{H} 3$ and $\mathrm{H} 7$ subtypes in their sera by ELISA (Meseko et al., 2016). Later, in a serosurvey conducted in Nigeria employing nucleoprotein-based ELISA, 173 out of 284 animals screened were found to be positive for the presence of EIV antibodies. Thus, a thorough screening is warranted in these areas to carve out the clear picture of the disease status and to adopt better control programs (Meseko et al., 2016). Sequencing of three H3N8 isolates from Morocco namely A/equine/Nador/1/1997, A/equine/Essaouira/2/2004 and A/equine/Essaouira/3/2004 showed that A/equine/Nador/1/1997 had relatedness with European lineage while A/equine/Essaouira/2/2004 and A/equine/Essaouira/3/2004 had homology with A/equine/Fontainbleu/1/1979. A/equine/Essaouira/2/2004 and A/equine/Essaouira/3/2004 also showed 12 substitutions in NS1 protein when compared with the reference A/equine/Miami/1963 strain (Boukharta et al., 2015).

\section{Asia}

During 2007-2008, China and its neighboring countries; Mongolia, India and Japan were invaded by various EIV strains (Qi et al., 2010). Further, phylogenetic analysis revealed that the Chinese strains, Indian strain (Jammu-Katra/6/08) and the Mongolian strain (Mongolia/1/08) were of Florida sublineage clade 2 type. All strains were derived from European strains of this clade as the Newmarket/1/07 and Cheshire/1/07 strains but were unrelated to Japanese strains isolated around the same time (Florida sublineage clade 1) or to Chinese strains isolated in the 1990s (European lineage). There were some unique amino acid changes in the antigenic sites in Asian strains of Florida sublineage clade 2 . The loss of a glycosylation site in the Chinese Liaoning/9/08 strain, leads to evolution of few new characteristics (Qi et al., 2010).

Since 2007, several outbreaks of EI have occurred in Kazakhstan, western Mongolia, India, and western China and all these have similarities with EIVs circulating in the same period in neighboring countries (Karamendin et al., 2014). Genetic characterization of the viruses revealed the formation of an EIV cluster and continued evolution of this lineage 
in central Asia between 2007 and 2012. The main genetic changes observed were in the HA gene without any antigenic drift. Recently, H3N8 A/Equine/Kyonggi/SA1/2011 (KG11) was isolated in Korea which had naturally truncated NS1 protein coding gene (Lee et al., 2017). Recently, genome of two equine influenza strains namely A/equine/Kostanay/9/2012(H3N8) and A/equine/LKZ/9/2012(H3N8) isolated from Kazakhstan was sequenced completely. It was reported that though the isolates were isolated at the same time there was sequence difference at some points indicating the evolution of equine influence (Burashev et al., 2018).

In India, the influenza like symptoms in equines were first reported in 1964 from the Bombay Turf Club, Mumbai, where around 400 horses showed symptoms of coughing (Manjrekar et al., 1965). Since then, India has experienced two major epizootics, first of which was recorded during January to August 1987, which involved over 83,000 equines in north and central India (Uppal and Yadav, 1987; Uppal et al., 1989). Two virus isolates of H3N8 subtype namely Ludhiana/87 and Bhiwani isolate were confirmed during the outbreak in 1987. Second epizootic was reported in 2008-2009 after a gap of 20 years, which initially started from Jammu and Kashmir and covered almost 14 states in the country (Virmani et al., 2008, $2010 \mathrm{a}, \mathrm{b})$. Based on the place of isolation, the isolates were named as A/equi-2/Ahmadabad, A/equi-2/Jammu-Katra/08 and A/equi-2/Mysore/08. HA gene of the isolates were analyzed phylogenetically which showed relatedness Florida sublineage Clade 2 in American lineage ( $\mathrm{H} 3 \mathrm{~N} 8)$ and also very similar to Chinese isolates of 2007-2008 (Virmani et al., 2010b). Similarly, analysis based on $\mathrm{M}$ gene showed homology of $98.41 \%$ and 99.54\% with other clade 2 Asian origin viruses for M1 and M2 amino acids sequences, respectively. Asian, Chinese and Mongolian isolates had three and four unique amino acid residues in the M1 and M2 proteins (Virmani et al., 2011). Phylogenetic analysis of the NA gene demonstrated that few Indian isolates differed from the Jammu-Katra/06/08 isolate. The Indian isolates were clubbed in Yokohama/10 isolate subgroup together with Chinese, Mongolian, and Kazakhstan isolates (Bera et al., 2013).

In the year 2007, an outbreak had been reported in China among Asian wild horses (Equus przewalskii). The virus had been isolated and completely sequenced and then designated as strain A/equine/Xinjiang/4/2007 which showed 99\% homology with Florida-2 sublineage rather than with strain A/equine/Qinghai/1/1994 (European lineage) responsible for previous outbreaks in China (Yin et al., 2014). In March 2017, an EIV outbreak in donkeys from Shandong province of China was reported where the virus was found to be A/donkey/Shandong/1/2017 (H3N8) belonging to the Florida sublineage clade 2 . Amino acid sequence comparison with the vaccine strain $\mathrm{A} /$ equine/Richmond/1/2007 showed substitutions at $\mathrm{A}, \mathrm{B}$, and $\mathrm{C}$ antigenic regions. The report suggested the circulation of newly emerging EIV in donkeys in China (Yang et al., 2018).

The Japanese EIV isolate Kanazawa/07 phylogenetically relates to American sublineage Florida virus clade (Ito et al., 2008). Some scholars have claimed that the 1889 human pandemic culprit was H3N8 EIV (Xie et al., 2016). An EIV isolate with truncated NS1 gene was isolated in South Korea which belonged to Florida sublineage clade 1. Truncation in the NS1 gene has not affected the replication of the virus (Na et al., 2014).

During the period 2015-2016, an outbreak of EI among equines of several districts of Khyber Pakhtunkhwa Province of Pakistan was noticed. An extensive epidemiological survey was conducted during the outbreak and it was found that A/equine/Pakistan/16 viruses was suggested to be outcome of reassortment between equine and avian influenza viruses as it possessed $\mathrm{H} 3 \mathrm{~N} 2$ or $\mathrm{H} 7 \mathrm{~N} 3$ like $\mathrm{M}$ and $\mathrm{NP}$ genes which was unique compared to other viruses (Khan et al., 2017).

Turkey reported their first EIV outbreak in the year 2013 and the virus was found to be a Florida clade 2 sublineage H3N8 which was similar to the one circulating in Europe (Gahan et al., 2017). Influenza virus A (A/camel/Mongolia/335/2012[H3N8]) has been isolated from camel in Mongolia, which is more evident of expansion in the host spectrum of this virus (Yondon et al., 2014). Survey carried out in the four provinces of Mongolia during 2016-17 showed that seven samples to be positive by qPCR and two samples were suspected positive for EIV out of 680 nasal swabs of horses examined but none yielded growth in MDCK cell line. Similarly, there was no positive case observed out of 131 camels tested. This study reported a sporadic incidence of enzootic EIV in Mongolia (Sack et al., 2017).

\section{Australia}

In Australia, the first outbreak of EIV was reported in the year 2007. The major outbreak appeared in New South Wales and Queensland affecting more than 1,400 equines within a month (Burnell et al., 2014).

\section{Disease Transmission}

The virus transmission occurs by inhalation through aerosol that can spread effectively through air up to $1-2 \mathrm{~km}$ of distance. Droplet infection plays a major role in the transmission as nasal discharge/fomites aid in animal to animal transfer (Timoney, 1996; Easterday et al., 1997). Horse-to-horse spread is fairly rapid and faster than other respiratory infections in the equine species (Chambers, 2014). International trade and traffic also leads to spread of disease to disease free zones of the world. Virus can endure for 3 days in the environment leading to the spread in other animals through fomites. The incubation period is $1-3$ days and the infected horses have been found to shed the virus up to 10 days via nasal discharge (Daly et al., 2004). Crowded housing practices of equines usually aid in the fast spread of the EIV (Figure 3).

Being a contagious disease, the rate of EIV infection is almost 100 per cent in unvaccinated horses. Age groups of 1-5 yearold naïve equines are more susceptible to EIV. Immune status of the animals plays an important in the onset of disease. Partially immune animals tend to become infected sub-clinically. Further, the spread of virus in partially immune animals is slower than in naïve animals (Landolt, 2014). EIV is a self-limiting sterile disease in horses since the virus does not persist in recovered animals (Cullinane and Newton, 2013). It was speculated that interspecies jump to dogs might be due to proximity with infected horses as 


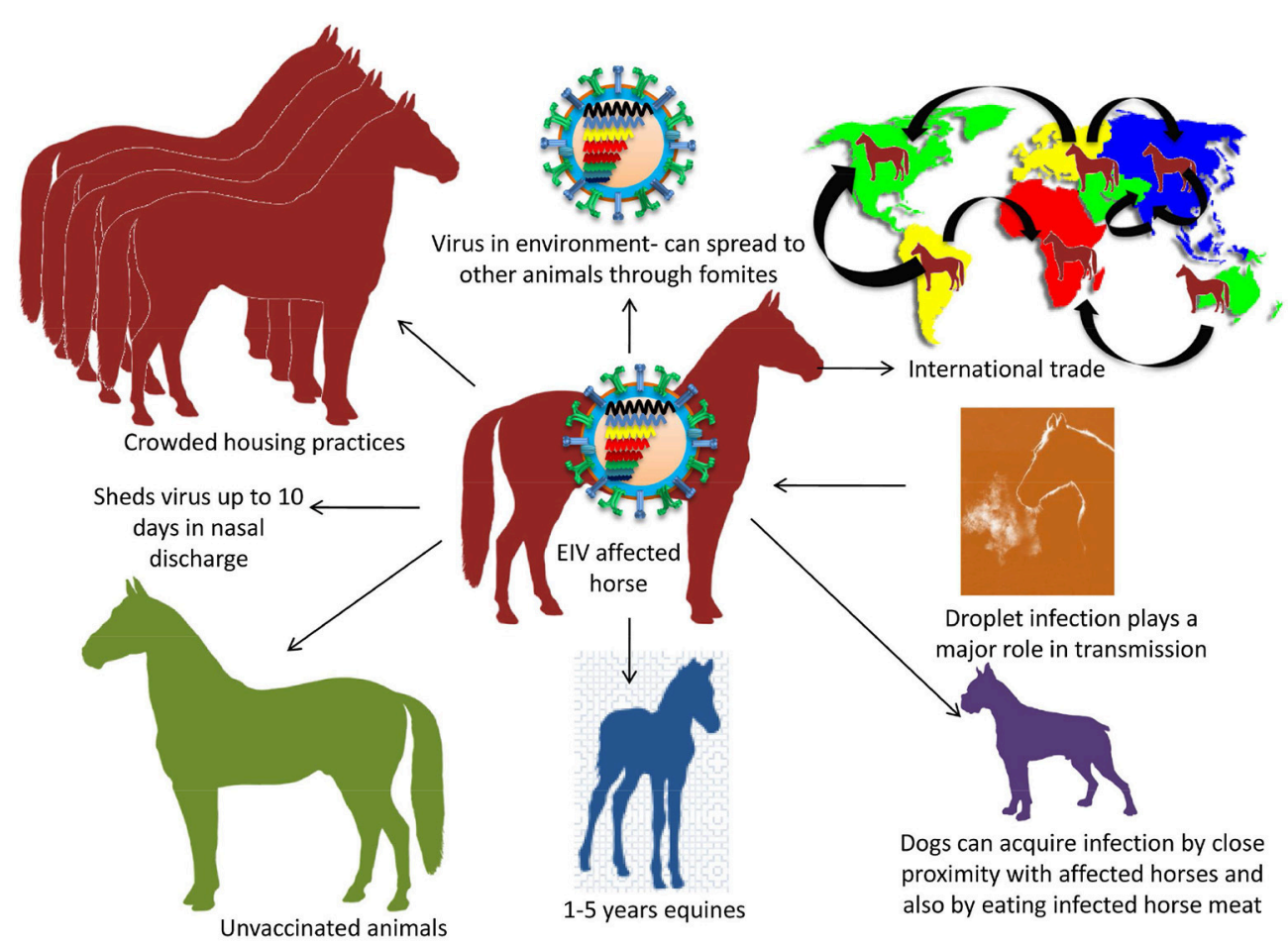

FIGURE 3 | Transmission of EIV. Droplet infection is an important mode of transmission. Transmission between animals includes crowded housing practices, non-vaccination, young horses of 1-5 years and international trade. Dog gets EIV by consuming infected dead horse meat.

happened in the first report of H3N8 in dogs in Florida, 2004 and/ or by eating the infected horse-meat (Crawford et al., 2005; Newton et al., 2007).

\section{Cross-Species Transmission}

Influenza virus shows partial host restriction and this characteristic is attributed to the HA gene. HA as a viral receptor binding protein, binds to the sialic acid (SA) host cell receptors. Binding is dependent upon the SA species (N-acetylneuraminic acid or N-glycolneuraminic acid) and its linkage with galactose moiety; either $\alpha(2 \rightarrow 6)$ linkage or $\alpha(2 \rightarrow 3)$ linkage. Human influenza viruses prefers SA $\alpha(2 \rightarrow 6)$-gal in $\mathrm{N}$-acetylneuraminic acid form, whereas avian, equine, and canine influenza viruses prefer binding to SA $\alpha(2 \rightarrow 3)$-gal in N-glycolylneuraminic acid form (Ito and Kawaoka, 2000). HA gene analysis has thrown much light on the evolution of equine and canine influenza viruses (Shi et al., 2010). Comparing the sequences of EIV isolated from equine and canine host showed differences or changes that occurred to meet the requirement for host cell adaptation and tropism. But not much change has been found to occur in the influenza virus biology during virus interspecies jumping (Collins et al., 2014; Feng et al., 2015). The canine influenza virus (CIV), A/canine/Colorado/30604/2006 (CO06, $\mathrm{H} 3 \mathrm{~N} 8$ ) evolved from an equine strain found to be only mildly pathogenic in equines due to a change in receptor preference acquired for viral entry into the host cell during mutation (Yamanaka et al., 2010). EIV have limited host specificity with the exception of reports of $\mathrm{H} 3 \mathrm{~N} 8$ virus transmission in dogs
(Kirkland et al., 2010). A limited transmission of EIV H3N8 has been reported among dogs in the United Kingdom as well as Australia (Parrish et al., 2015). The equine and canine H3N8 viruses have minimum difference biologically and both show mutation in PA-X protein (Feng et al., 2015, 2016). Simultaneous circulation of $\mathrm{H} 3 \mathrm{~N} 8$ viruses in dogs and horses makes bidirectional virus transmission possible (Rivailler et al., 2010). Studies have indicated the inability of H3N8 CIV isolates to replicate and spread in equids and suggested the involvement of factors other than receptor binding specificity in infection with EIV (Kirkland et al., 2010; Pecoraro et al., 2013; Landolt, 2014). Reciprocally, equine H3N8 lineages are absent in dogs (Rivailler et al., 2010). It is interesting to note that due to substitution of amino acid in the binding site there may be modification in the $\mathrm{H} 3 \mathrm{~N} 8$ replication in the canine respiratory tract (Collins et al., 2014). In line, experimental transmission of EIV H3N8 to cats has also been reported ( $\mathrm{Su}$ et al., 2014), indicating the wider host spectrum of EIVs in the event of exposure. In the year 2012-2013, EIV (H3N8) was also isolated from a Bactrian camel in Mongolia (Yondon et al., 2014). Out of 460 nasal swabs only one isolate A/camel/Mongolia/335/2012[H3N8] was recovered highlighting the need for further investigations in camels to find the pathobiology of EIV in camels.

The phylogenetic analysis of $\mathrm{H} 3 \mathrm{~N} 8$ viruses isolated from dogs and horses revealed monophyletic and distinct evolution of both viruses. However, analysis of a limited number of EIVs suggested substantial separation in the transmission of viruses causing clinically apparent influenza in dogs and horses (Rivailler 
et al., 2010). Yamanaka et al. (2009) tested the possibilities of interspecies transmission of EIV to dogs due to close contact with experimentally EIV infected horses. The infected horses were kept with healthy dogs in three groups in close proximity for 15 days and HI test revealed sero-conversion in all with viral shedding in dogs of two groups without apparent clinical symptoms. The same study was performed in inverse order by Yamanaka et al. (2012a) with healthy horses and CIV infected dogs kept in close contact to investigate the interspecies transmission. Though all the dogs infected with CIV presented clinical signs of lung consolidations after euthanasia, none of the horse showed clinical signs, virus shedding, seroconversion or lesions in the respiratory tract. These findings thus revealed that a single dog infected with CIV is not sufficient enough to be a source of CIV infection in horses. Short et al. (2015) have reviewed influenza A viruses comprehensively by describing interspecies virus transmission and analyzing the current knowledge regarding adaption of influenza viruses to a new host.

Two isolates of H3N8 EIV were isolated from swine in China when pigs were screened for swine influenza ( $\mathrm{Tu}$ et al., 2009). Though pigs possess both $\alpha-2,6$ galactose and $\alpha-2,3$ galactose sialic acid receptors, a study with EIV does not produce fever and other notable histopathological changes. H3 HA of influenza viruses has extended pathogenic potential, but analysis showed that evolution of $\mathrm{H} 3$ from equine and canine origin is different from H3 of swine, avian, and human viruses (Shi et al., 2010). Further, the potential of $\mathrm{H} 3 \mathrm{~N} 8$ influenza virus from canine, equine, avian, and seal origin has been tested for its capability to infect pigs. Avian and seal $\mathrm{H} 3 \mathrm{~N} 8$ viruses replicate substantially causing detectable lesions in pigs without previous adaptation. No specific antibodies against hemagglutinin in any $\mathrm{H} 3 \mathrm{~N} 8$ infected pigs could be detected. Therefore, special attention is required toward viruses of the $\mathrm{H} 3 \mathrm{~N} 8$ subtype since these may infect pigs without detectable anti-hemagglutinin antibodies and thereby pose a risk of genetic reassortment where pigs act as mixing vessel for influenza viruses (Solórzano et al., 2015).

\section{Equine Influenza and Human Infection}

Although there are sparse reports of EIV infection in man, the data regarding the phenomenon originated from Mongolia, where horse-to-man population ratio is highest in the world. It is presumed that the probable cause of human pandemic in year 1889 is supposed to be due to the involvement of H3N8 EIV (Elbadry et al., 2014; McAuley et al., 2015). However, to note due to close association (both temporal as well as geographical) between human as well as equines, influenza-like disease epizootics had been observed before the advent of various serological and molecular assays to detect the virus (Morens and Taubenberger, 2010). It is reported that the development of influenza-like illness (ILI) among Mongolian children occurred after exposure to infected equines (Khurelbaatar et al., 2014). Few anecdotal reports are also suggesting the suffering of Mongolian children with ILI due to the exposure to EIV infected horses (Xie et al., 2016). After the H3N8 epizootic in New South Wales and Queensland, Australia in 2007, a cross sectional study was carried out enrolling 89 humans exposed to infected horses along with 11 controls. Hemagglutination, micro-neutralization, and enzymelinked lectin assays were carried out in serum samples to detect $\mathrm{H} 3 \mathrm{~N} 8$ antibodies, but with a low titer of antibodies indicating the absence of acute infection, which could be the outcome of cross reacting antibodies (Larson et al., 2015). Also, the experimental data revealed that the $\mathrm{H} 3 \mathrm{~N} 8$ virus could not attenuate following passage in humans, as it was still capable of infecting and causing illness in horses (Couch et al., 1969). In a cohort study conducted among Mongolian adults, after occupational exposure to EIV infected horse, ILI was observed, and upon quantitative real time PCR and virus culture, 36\% ILI cases were found influenza A positive without evidence of EIV (Khurelbaatar et al., 2013, 2014). During Australian outbreak of EI in the year 2007, human samples collected showed only little seropositivity for the equine strain, which was concluded by the fact that human vaccines had cross-reactivity to this virus or humans were not susceptible to EIV (Burnell et al., 2014).

\section{EQUINE INFLUENZA: THE DISEASE}

\section{Clinical Manifestations}

Clinical signs of EI include the loss of appetite, fever, general weakness, poor performance, harsh dry cough, hyperemia of nasal and conjunctival mucosae, tachycardia, dyspnea, stiffness in legs due to limb edema and muscle soreness, enlarged lymph nodes, serous nasal discharge, which may turn yellowish due to secondary bacterial infection and abortion. There is high morbidity rate in EI while mortality rate is low, and death usually occurs due to pneumonia as a sequela. In rare cases, myocarditis and chronic obstructive pulmonary disease is seen especially when horses return to training too soon. Encephalitis in horses and rapid fatal pneumonia in foals and donkeys has also been recorded but its pathogenesis is not clear (Gerber, 1970; Radostits et al., 2003; Newton and Mumford, 2005; Cullinane et al., 2006; Daly et al., 2006; Landolt et al., 2007). Both the subtypes produce similar clinical symptoms, but these are more severe in case of H3N8 infection (Chambers, 2014). Incubation period usually depends on the immune status of the animals (varies from $18 \mathrm{~h}$ to 5 days under experimental settings) and can be very short, up to $24 \mathrm{~h}$ in naïve horses (Cullinane and Newton, 2013). Fever of 39.4-41. $1^{\circ} \mathrm{C}$ may last for $2-3$ days. Carrier status does not exist, but sub-clinical infection in recently vaccinated animals may go unnoticed. Usually horses recover within 1-2 weeks, while severely sick animals require a month time to recover (Cullinane and Newton, 2013). Clinical signs in dog include fever, cough, occasionally suppurative bronchopneumonia and per acute death (Crawford et al., 2005).

\section{Pathogenesis and Pathology}

EIV mainly damages the upper and lower respiratory tract's ciliated epithelial cells thereby causing inability to clear foreign substances. The spike glycoprotein, HA, attaches with sialic acid receptors localized on host cell surface and subsequent receptor-mediated endocytosis process proceeds to deliver the virus particle inside of cell and remain in an endosome. Lower $\mathrm{pH}$ environment in this cell apartment triggers fusion process of membranes of the virus and endosome. Acidic $\mathrm{pH}$ alters 
not only alters the conformation in HAO but also opens the M2 ion channel and acidifies the viral core and the vRNP (composed of proteins NP, PA, PB1, and PB2) enters the nucleus through host cell's cytoplasm. The viral RNA dependent RNA polymerase (RdRp) initiates the RNA synthesis internally on viral RNA and utilizes host cell's machinery for its own purpose. After completing the viral proteins synthesis vRNPs leave the nucleus all that is left for the virus to do is form viral particles and leave the cell. Being an enveloped entity, it comes out the host cell's through budding (Radostits et al., 2003; Figure 4). Replication of EIV leads to virus particles being released from one cell to enter another cell in the airway, thereby damaging the respiratory tract leading to necrosis of the respiratory epithelial cells, protein rich fluid exudation into the airways, cilia getting clumped and impairing the muco-ciliary apparatus.

Horse respiratory epithelium possess high level of Neu5Gc2$3 \mathrm{Gal}$ moiety, which is essential for replication of the virus (Suzuki, 2000). EIV NA possess higher affinity for this moiety. This is important at the early stage of infection in order to release the progeny from the infected cell (Takahashi et al.,
2016). Cells infected with EIV undergo apoptosis, which is the common pattern of cell death (Hinshaw et al., 1994). Activation and cleavage of caspase is essential for cytotoxicity caused by the virus (Lin et al., 2002). Non-structural protein 1 (NS1) of EIV is pivotal in disease pathogenesis and differences observed in disease severity due to variation in this protein (Elton and Bryant, 2011). NS1 facilitates virus replication along with having an inhibitory effect on anti-viral strategies applied by the host. Viral replication is supported by NS1 by inhibiting host RNA processing machinery and in turn utilizing these host components for viral RNA transcription preferably. NS1 further inhibits the host anti-viral response by preventing activation of various host defense components such as interferon regulatory factor 3 (IRF-3), NF-kB, and other transcription factors (Barba and Daly, 2016). Cytotoxic T cell response is generated against M, NP, and PB2 which helps in viral clearance (Landolt, 2014). Of interest, eukaryotic cells express a wide range of small regulatory RNAs, including miRNAs that have the potential to inhibit the expression of mRNAs (e.g., viral) showing sequence complementarity. However, a study hypothesized that human viruses including influenza $\mathrm{A}$ viruses might have evolved in a

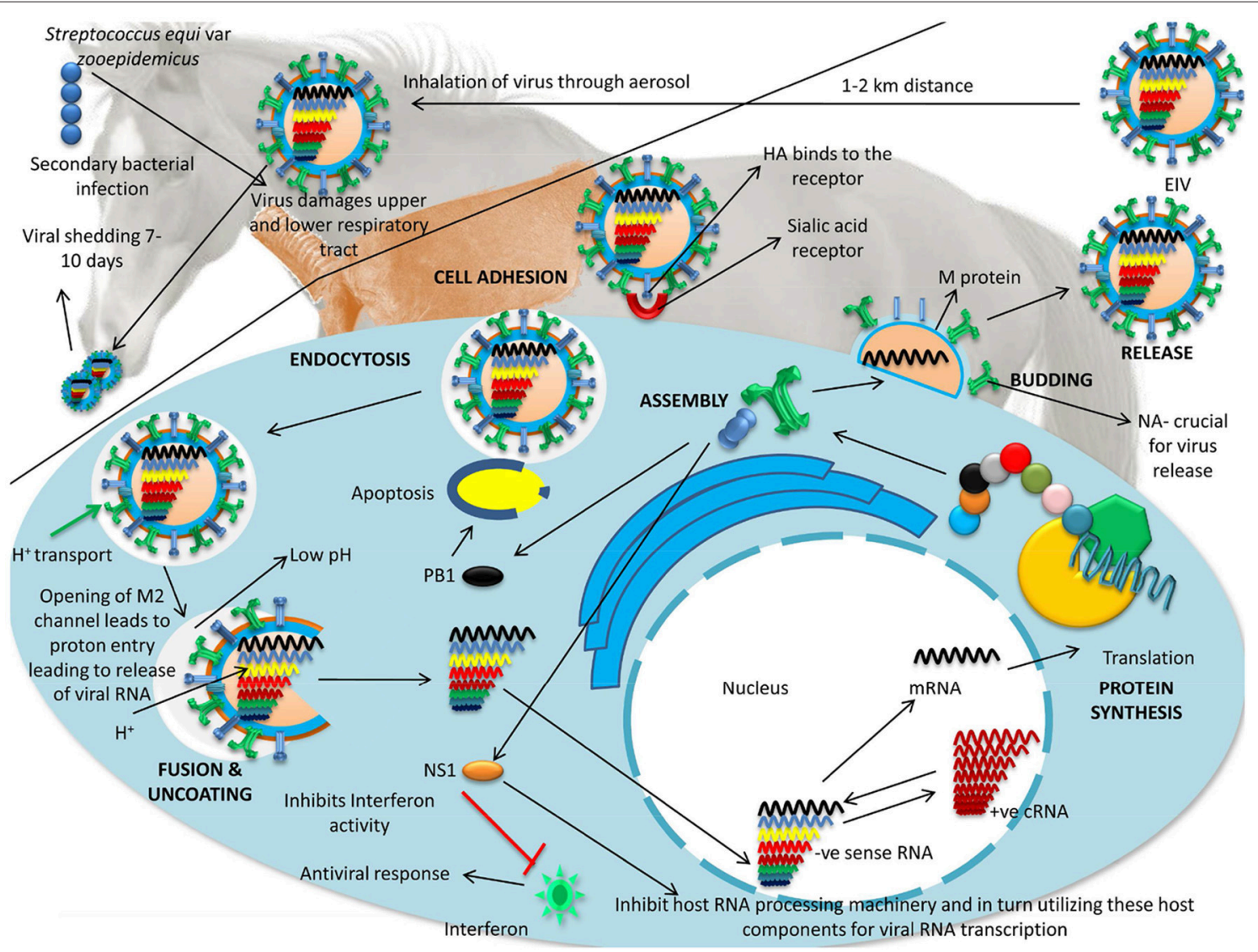

FIGURE 4 | Replication and pathogenesis of EIV. EIV damages the upper and lower respiratory tract's ciliated epithelial cells thereby causes inability to clear foreign substances. Spike glycoprotein HA fastens to the receptors present on the respiratory epithelial cells and it enters the cells by endocytosis. After endocytosis, EIV undergoes fusion and uncoating. Opening of M2 channel leads to proton entry and subsequent release of viral RNA followed by synthesis of viral structures leading to assembly of EIV. EIV is released from the infected cells by the process of budding. 
manner so that it resists endogenous inhibition by miRNAs (Bogerd et al., 2014).

Viral shedding can be observed for a period of 7-10 days, while viral genome (RNA) can be detected for 15 days or more by PCR (Chambers, 2014). This infection is seldom fatal in horses except in colostrum (specific immunoglobulin rich) deprived newborn foals (Chambers, 2014). Due to accumulation of fluid in the respiratory tract, there are chances of secondary bacterial infection and organisms like Streptococcus equi var. zooepidemicus increases the inflammation leading to bronchopneumonia (Radostits et al., 2003). Thus, EI disease is further worsened by concurrent bacterial infection acting as a helping hand in fatal episode of equine influenza (Daly et al., 2004). Respiratory epithelium takes around 3 weeks to recover which aggravates or provide gateway for secondary bacterial infection (Landolt, 2014; Na et al., 2016).

Bronchiolitis is the common lesion noticed with serous exudates bilaterally. Gross pathology reveals diffuse to very extensive pulmonary consolidation and histological changes like necrosis of bronchioli and alveoli, infiltration of neutrophils, formation of hyaline membranes and airway epithelium undergoing hyperplasia and squamous metaplasia (PattersonKane et al., 2008). Studies revealed that a secretory layer of mucous is present in the nasal cavity of the equine species that can prevent the attachment of HA protein of influenza virus. Similarly, the nasal passage also possesses sialo-receptors that can mask receptors specific to influenza (Scocco and Pedini, 2008). EIVA/equine/South Africa/2003 in dogs revealed similar pathology as that of CIV causing extensive damage to the respiratory epithelium. This damage was more extensive than that caused by 1963 EIV in canines. This shows that the recent EIV strains can infect dogs readily (Gonzalez et al., 2014). Pavulraj et al. (2015) have studied the pathology of EIV (H3N8) in a murine model. The pattern of disease progression, lesions and virus recovery from nasal washings and lungs in mice were found comparable to natural and experimental EIV infection in equines. These findings establish $\mathrm{BALB} / \mathrm{c}$ mice as an attractive small animal model for studying EIV (H3N8) infection. Authors also reported that $\mathrm{BALB} / \mathrm{c}$ mice could be a better candidate for testing the EIV vaccines before trial in equines (Pavulraj et al., 2017).

\section{Diagnosis}

There is an array of diagnostic techniques available for EIV infection viz. isolation of virus, serological assays, antigen and genomic RNA detection (Mumford, 1990; Chambers et al., 1994; Gupta et al., 2003; Cullinane et al., 2006; Landolt et al., 2007; OIE, 2008; Cullinane and Newton, 2013; Kapoor and Dhama, 2014). However, the clinical diagnosis of EIV remains a challenge, where high fever and dry cough are predominantly noticed. The differential diagnosis includes other respiratory diseases like equine adenoviral infection, equine herpesvirus infection, equine rhinopneumonitis, equine viral arteritis, travel sickness (pleuropnemonia), and also strangles (Radostits et al., 2003).

Swab samples from nasopharyngeal region can be taken immediately after the onset of clinical symptoms (i.e., within 35 days). Choice of sampling must be very careful as it affects the accuracy of results. Nasopharyngeal swab yields more density of virus than the nasal swabs (Chambers and Reedy, 2014a). Transportation of the samples in appropriate ice-cold containers is essential. If samples are to be transported for more than 2 days, these should be kept at $-60^{\circ} \mathrm{C}$ or at lower temperatures. Allantoic or amniotic routes are performed for isolation of EIV and fluids from these cavities are subjected to HA and a titer of more than 16 is considered positive. If the titer is low then further blind passages have to be given. Isolation of virus is usually done in embryonated chicken eggs by amniotic route. Chorioallantoic membranes can also be used for isolation of the virus and instead of HA, qRT-PCR can be employed for detection of the virus rapidly (Gora et al., 2017). Cell lines like Madin Darby canine kidney (MDCK) are suitably used for virus isolation (Easterday et al., 1997). Both chicken egg and MDCK cell lines allow viral mutations, but embryonated eggs are generally preferred for isolation due to comparatively lesser heterogeneity in them (Chambers and Reedy, 2014b). Samples that show isolation negative results should be passaged again and up to five blind passages may be necessary for samples from vaccinated horses.

Seroconversion can also be employed for diagnosis of the disease and assays such as $\mathrm{HI}$, single radial hemolysis (SRH), single radial immunodiffusion (SRID) and enzyme linked immunosorbent assay (ELISA) are commonly used (OIE, 2008). Antigen capture ELISA for $\mathrm{H} 3 \mathrm{~N} 8$ virus using a monoclonal antibody against nucleoprotein can be employed at places lacking facilities for isolation of the virus (Cook et al., 1988; Livesay et al., 1993). ELISA to detect antibodies against nucleoproteins can be used to differentiate infected animals from vaccinated ones as the same did not detect antibodies generated after canary pox vectored vaccines for this virus that contain HA protein (Kirkland and Delbridge, 2011; Galvin et al., 2013). It has been suggested to use ELISA (cell-based) for measuring antinon-structural (NS1) protein antibodies which has found its application in differentiating infected from vaccinated animals (DIVA) in equines (Rozek et al., 2011). Characterization of the isolate can be done by HI using specific antisera, but due to the presence of inhibitors of hemagglutination (such as $\alpha-2$ macroglobulin) in equine sera complicates the interpretation of this test (Chambers, 2014). This can be overcome by pre-treating the sera with Tween-80 and ether or Kaolin (Chambers, 2014; Chambers and Reedy, 2014c). For identification of susceptible population of horses and for the purpose of disease investigations related to outbreak in immunized horses, single radial hemolysis (SRH) test has been found to be useful (Gildea et al., 2010, 2011). SRH tests give higher correlation between serum antibody titer and protection level from the disease and also indicate sterile immunity (Chambers, 2014; Chambers and Reedy, 2014c). SRID is a higher version of chick cell agglutination test and there is no high variation among tests (Wood et al., 1983). Paired serum samples should be used for serological tests and seroconversion (as reflected by a four times higher antibody titer) indicates recent influenza virus infection.

Tests aiming at genomic material detection like reverse transcription-polymerase chain reaction (RT-PCR) and real-time PCR can be used for EIV diagnosis (Donofrio et al., 1994; Foord 
et al., 2009; Read et al., 2012). A qRT-PCR test for the matrix gene of type A influenza viruses was used during the 2007 Australian EI outbreak to confirm the presence of the virus in animals to be exported (Diallo et al., 2011). However, at the end of the outbreak, four horses were found positive due to contamination of the samples with the vaccine (Diallo et al., 2011). A real-time RTPCR (rRT-PCR) assay has also been employed for the detection of virus in the nasal swab of horses in Mongolia (Yondon et al., 2013).

The use specific primers in RT-PCR assay for conserved region of this virus was found to give rapid results with high sensitivity even in case where viral load in excretions was very less. Furthermore, viruses of unknown lineages could also be detected by using such primers (Aeschbacher et al., 2015). Multiplex RTPCR test to detect H3N8 has been developed which is expected to detect newly EIVs (Lee et al., 2016). In one study, it was found that DFA (rapid antigen detection test kit) used to detect nucleoprotein in nasal swabs is a very sensitive antigen test and can act as supportive test for laboratory diagnosis of EIV in clinical samples (Galvin et al., 2014). Using specific primers, EIV typing can also be done and RNA-DNA hybridization test has also been reported (Gupta et al., 2003). Nested-PCR has also been developed which showed that it is useful for diagnosis of EIV (Oxburgh and Hagström, 1999). Immuno-PCR, a more sensitive assay than the RT-PCR has been developed for detection of NS1 protein (Ozaki et al., 2000). Real-time light cycler RT-PCR has been reported to be more sensitive than either the isolation of virus or ELISA (Quinlivan et al., 2005).

RT-PCR followed by sequencing has been used for diagnosis and subtyping of the neuraminidase (Alvarez et al., 2008). TaqMan RT-PCR targeting nucleoprotein (NP), matrix (M) and HA gene of both H7N7 and H8N8 subtypes has also been developed. The results of this developed assay do not cross react with any of the other known equine respiratory viruses (Lu et al., 2009). Reverse transcriptase-loop mediated isothermal amplification (RT-LAMP) has been developed to detect HA gene of both H3N8 and H7N7 EIV, which is more sensitive than RT-PCR. Further, this test can also be used to differentiate H3N8 and H7N7 in clinical samples (Nemoto et al., 2011, 2012). Recently, insulated isothermal RT-PCR (iiRT-PCR) has been developed to detect HA3 gene of EIV, which is a highly sensitive and specific test (Balasuriya et al., 2014). The test involves three steps viz. rehydration of lyophilized reagents, sample nucleic acid addition and then placing on POCKIT ${ }^{\mathrm{TM}}$ Nucleic Acid Analyzer device. This test is rapid as it requires only $1 \mathrm{~h}$ to complete the reaction on this portable device and does not require any post-amplification processing (Balasuriya, 2014; Balasuriya et al., 2014). Pyrosequencing has also been recently implicated in identifying clade differentiation of EIV at the time of outbreak (Bernardino et al., 2016). Many rapid antigen detection tests (ImmunoAce Flu, BD Flu examan, Quick chaser Flu A, B, ESPLINE Influenza A\&B-N, etc.) have been developed for diagnosis of this virus. However, the sensitivity of these tests is very low, also they detect virus for short period of time as compared to the molecular tests such as RT-PCR thus giving higher rate of false negative results (Yamanaka et al., 2008b, 2016a). A sensitive silver amplification immunochromatography was developed for early detection of EIV (Yamanaka et al., 2017a).

\section{PREVENTION AND CONTROL}

\section{Vaccines}

To deal with emerging viral diseases of equines including EI, it is mandatory to strengthen the medical/veterinary services with adopting appropriate preventive measures such as vaccines and adjuvants (Bayry, 2013; Chambers and Balasuriya, 2016; Paillot et al., 2017). It has been seen that vaccination has been practiced since 1960s, however, its efficacy is still a matter of debate due to the use of less potent vaccines, improper vaccination schedule and also use of outdated virus strains, and due to continues drift in the viral genome (Bryans et al., 1966; Minke et al., 2004; Mathew et al., 2006; Meeusen et al., 2007). Hence, use of the virus from the most recent outbreak as vaccine renders better protection (Barbic et al., 2009). Moreover, experience from the field cases has shown that vaccination was successful in preventing H7N7 infection but outbreaks due to $\mathrm{H} 3 \mathrm{~N} 8$ are prevalent both in vaccinated and non-vaccinated animals. H3N8 subtypes are the main cause of EIV infection and vaccine virus different from prevailing subtypes leads to subclinical infection, which is followed by viral shedding from vaccinated animals as well. This further contributes to the spread of disease (Daly et al., 2004). Influenza A viruses are able to evade host immunity even in vaccinated horses, and study of intra- and inter-host evolution of EIV in vaccinated horses, revealed the similar level and structure of genetic diversity with those in naïve horses. However, intra-host bottlenecks were more stringent in vaccinated animals and mutations were present near putative antigenic sites as shown by Murcia et al. (2013). The virus isolates collected from the outbreak area determines the vaccine strain selection, and hence essentially surveillance programmes should have sufficient funding with active involvement of equine veterinarians (Elton and Cullinane, 2013).

Antigenic drift at the HA gene (a major protein of influenza A virus) led to vaccine failure in various parts of the world (Mumford and Wood, 1993; Wilson, 1993). Genetic reassortment taking place during a mixed infection can lead to the development of new strains and ultimately vaccine failure (Bryant et al., 2009). To deal with this problem, continuous checks and monitoring through surveillance programs and updating of vaccines with recent strains remains the best and effective way in prevention and control of this disease. Such methods have proven to be successful in Ireland during 20072010, where regular surveillance provided scientific or effective control of EI disease. The study revealed that the EIV strain changed from prevalence of Eurasian lineage to clade 1 and clade 2 of Florida lineage. Accordingly, changes made in vaccine strains lead to scientific or effective control of the disease (Gildea et al., 2012). Similar results were obtained by proper surveillance programs in South America where incidence of this disease have reduced prominently after incorporation of Florida clade 2 strains in vaccines (Perglione et al., 2016). A study was conducted in United Kingdom to know the antigenic changes occurred in EIV isolates during 2013-2015 so as to 
get a clear picture on the efficacy of vaccine. Result showed that Florida sublineage clade 2 was diverging. The study also suggested inclusion of Florida sublineage clade 1 and 2 in the vaccine for EIV (Rash et al., 2017). Thus, an epidemiological surveillance of influenza virus along with monitoring of impact of immunization is extremely important. The disease control is influenced by antigenic variation of the virus, target group, goal of immunization, rate of antigenic variation, and vaccine composition (Horspool and King, 2013).

There is protection of ponies from vaccinated dams but antibodies titer decline as the days passes, hence it is essential to protect the ponies by vaccinating with the recent virus strain prevalent or circulating in the population (Townsend et al., 1999; Meeusen et al., 2007). Vaccination will not completely eliminate the chance of infection and booster vaccines are essential to keep the disease under control (Nelson et al., 1998; Daly et al., 2004; Yamanaka et al., 2008a). Herds with 75\% vaccination coverage exhibit better disease control exposed to virulent infections. Considering vaccine efficacy, it is important to assess it's HA content because it is the main component that determine viral entry into the cell (Daly et al., 2004).

The World Organization for Animal Health (OIE) is the apex body to decide the strain to be used for vaccination in commercial vaccine preparations. Every year the molecular data of HA gene sequencing is taken into account and antigenic characterization is carried out by using reference sera to take cross protection studies results into account. This data is reviewed by Expert Surveillance Panel (ESP) constituting members from WHO and OIE. Then, they suggest whether there is a need to update the existing vaccine. Such program however failed by the disparity in the level of surveillance carried out in different countries (Cullinane et al., 2010). New strains are included only in case, where previously recommended strains are not providing optimum protection. Also, clinicians must be vigilant enough to decide which vaccine strain to be incorporated in the prophylactic regimen (Cullinane et al., 2010). Regular monitoring is required so that any mutation in the circulating virus needs to be identified timely and thereby the available vaccines can be updated accordingly. Recently in the year 2016, EIV vaccine in Japan has been updated with A/equine/Yokohama/aq13/2010 and study showed that combining both old and new vaccine provide better protection (Yamanaka et al., 2017b). Complete genomic sequences of both the vaccine strains namely A/equine/Yokohama/aq13/2010 and $\mathrm{A} /$ equine/Ibaraki/1/2007 that is being used in the vaccine strain in Japan from 2016 has been published very recently (Nemoto et al., 2018). Vaccines must be administered strategically and appropriately to obtain optimum immune response and desired protection against EIV in equines (Daly and Murcia, 2018).

To update the existing inactivated EI vaccine used in Japan it was decided to include Florida sublineage clade 2 virus. Study was conducted employing A/equine/Carlow/2011 (H3N8), A/equine/Richmond/1/2007 (H3N8) and A/equine/Yokohama/aq13/2010 (H3N8) and the results showed that A/equine/Yokohama/aq13/2010 had higher HI titer hence it was considered to be the better strain for updating the existing vaccine (Gamoh and Nakamura, 2017). If other countries also conduct such studies similarly then it will be very useful for them to implement such strategy when necessary to save equine population from the havocs of an outbreak.

The below section details the advances in designing and developing EIV vaccines and vaccination strategies that are actively being used for equine immunization.

\section{Killed/Inactivated Vaccine Adjuvanted With ISCOM-Matrix (Prequenza ${ }^{\circledR}$ )}

Commercially available EIV vaccines are killed vaccines of whole cell H7N7 and H3N8 subtypes (Park et al., 2003). The inactivated vaccines protect horses from disease with no viral shedding. Inactivated vaccines require booster regimen for better efficacy and are best suited for vaccinating dams so as to protect foals from infection. Formaldehyde, $\beta$-propriolactone, ethylene-imine, and thimerosal are frequently used for inactivating viruses for vaccine formulations. An inactivated EI vaccine elicits protective response against circulating strain of Florida clade 2 sublineage. Duvaxyn IE-T Plus ${ }^{\circledR}$ inactivated virus vaccine was given at the interval of 4 weeks and protection from clinical symptoms was observed with reduced viral shedding (Paillot et al., 2013a). Starting at 6 months of age, the vaccine is re-administered at an interval of 3-12 months based on the risk of infection. Killed vaccine adjuvanted with ISCOM-matrix (Prequenza ${ }^{\circledR}$ ) has been formulated and found to provide longer duration of immunity (Bengtsson, 2013). This vaccine was found safe to use in pregnant mares and foals (Heldens et al., 2009). Equip ${ }^{\mathrm{TM}}$ F (Schering Plough Animal Health, Hertfordshire, UK) vaccine contains a H7N7 strain and two H3N8 strains, each from American lineage as well as Eurasian lineage. It is an ISCOM-based vaccine which significantly reduces the clinical symptoms and prevent virus shedding in ponies (Paillot et al., 2008). It induced EIV-specific IFN- $\gamma$ production through activating Th1 cells (Paillot et al., 2006a). The study of Paillot et al. (2010) was focused on immunity in absence of updated vaccine strain. Ponies were immunized twice with commercial vaccine Duvaxyn IE-T Plus ${ }^{\circledR}$ with an interval of 14 days and challenged in a containment facility by exposure to a nebulized aerosol of a genetically different strain. The results indicated reduction in pyrexia and virus shedding. However, duration of protective immunity is shorter for a nonupdated vaccine and is prone for any further antigenic drift.

Adjuvants in vaccine are immune stimulating components, which aid in boosting humoral and cell mediated response (Horspool and King, 2013). Aluminum salts like aluminum phosphate and aluminum hydroxide, organic adjuvants like squalene, oil-based adjuvants like MF59, mycobacterial adjuvant like Freund's complete adjuvant and monophosphoryl-lipid A/trehalose dicorynomycolate (Ribi's adjuvant) are few good examples of adjuvants. They are aimed at presenting antigen to immune cells, targeting toward antigen presenting cells, and enhancement of cell-mediated immunity (Edelman, 2000). Now-a-days, it is suggested to use A/equi-1 and A/equi-2 strains similar to American and European lineages (Heldens et al., 2004). Certain vaccine virus strains used in inactivated vaccines show cross-protection as observed in case of Japanese strain A/equine/La Plata/1993 (LP93) and Florida lineage strains [A/equine/Carlow/2011 (CL11)] (Yamanaka et al., 2016b). However, Japanese strain A/equine/La Plata/1993 used in vaccine 
was not able to generate cross-neutralizing antibodies against Florida sublineage clade 2 (isolated from Ireland and UK) EIV due to single substitution (from alanine to valine) at 144 position in the antigenic A site of the HA gene (Yamanaka et al., 2015). Administration of combined inactivated equine influenza virus vaccine with equine herpes virus vaccine has shown increased immune response against EIV (Gildea et al., 2016). Few associated disadvantages with these inactivated vaccines are their poor immunogenicity and predominant short-term humoral immunity, which necessitates repeated immunization (Heldens et al., 2004).

In India, development of a low cost indigenously developed EIV vaccine was necessitated due to the suffering of more than 83,000 equines during 1987 (Uppal and Yadav, 1987). Indian Council of Agricultural Research-National Research Centre on Equines (NRCE) in collaboration with Animal Health Trust, Newmarket, U.K. has developed an EI vaccine employing A/eq/Ludhiana/87 isolate. Vaccine induces satisfactory humoral and protective immunity when challenged with live A/ Equi-2 viral isolates (Sussex/89 and Ludhiana/87) when administered in two doses 4 weeks apart. To prepare inactivated EIV vaccine, isolates from various regions of the country viz. Ahmadabad (Gujarat), Katra (Jammu), Gopeshwar (Uttarakhand), and Mysore (Karnataka) were cloned and A/eq/Katra (Jammu)/06/08 (H3N8) virus was used for updating the vaccine on the basis of sequence analysis. Inactivated vaccine along with aluminum hydroxide gel adjuvant was found to be protective and safe as tested in guinea pigs and horses. Vaccine trials conducted in 150 field horses showed development of protective immunity, without any untoward signs. Subsequent trials in thoroughbred horses also gave encouraging results as all the six animals showed protective immune response after booster dose (NRCE Annual Report, 2010).

\section{Subunit Vaccines}

Subunit vaccines encompass purified viral antigens. Among these, two main vaccines are the immune-stimulating complexes (ISCOM)-based vaccines or ISCOMATRIX vaccines. ISCOM based vaccines have ISCOM particles with cage like structures formed spontaneously by viral protein combination with cholesterol, phospholipids and Quillaja saponins. ISCOMATRIX are essentially like vaccines but don't possess cage like structure (Elton and Bryant, 2011). ISCOM based EIV vaccine induces strong antibody response along with elevated levels of IFN- $\gamma$ (Paillot et al., 2008). Use of ISCOM based EIV vaccine through intranasal route in systemic prime/mucosal boost vaccination program gave transient higher virus-specific IgA in nasal wash (Crouch et al., 2005). Since inactivated vaccines against EIV produce short-term antibody response other methods like ISCOM based vaccine technology has been developed in order to simulate natural infection. Cell mediated immune response is also stimulated by ISCOM based vaccines for EIV as indicated by high IFN- $\gamma$ production in peripheral blood lymphocytic cells (Paillot and Prowse, 2012). A study using A/eq/Kentucky/98 ISCOM based vaccine administered intramuscularly gave good protection when challenged with reference virus H3N8 of American lineage (Crouch et al., 2004). Recently, a subunit vaccine and a DNA vaccine based on HA stem region of A/equine/Argentina/1/93 (H3N8) virus was tested in mice and it showed $100 \%$ protection when challenged with equine strains while $70-100 \%$ protection with human strains (H3N8). The study also showed that challenge with human strain H1N1 $(\mathrm{A} / \mathrm{PR} / 8 / 34)$ did not protect the vaccinated animals, hence the developed vaccine protects animals only against homosubtypic strains (Ibañez et al., 2018).

\section{Cold Adapted (Ca) Vaccines}

These vaccines have been developed to aim at improving both humoral and cellular immunity, therefore mimicking the protective immunity generated by natural infection (Paillot et al., 2006b; Paillot, 2014). The Ca EIV vaccine strain is able to replicate efficiently in upper respiratory tract to generate local and systemic immune responses. The most advantageous part is that the Ca strain doesn't replicate in the lower respiratory tract, the niche of wild type influenza virus and therefore symptoms like bronchitis, pneumonia, and pulmonary edema do not occur (Townsend et al., 2001).

\section{Modified-Live Cold-Adapted Equine Influenza A2}

These vaccines are administered intra-nasally and have been found to be safe and reduced the onset of EIV outbreak (Chambers et al., 2001; Townsend et al., 2001). Intranasal vaccine resulted in local protection against EIV though the circulating level of antibody reduces as time progresses. Though, administration of this vaccine to yearlings was found to be safe, they are not recommended for use in pregnant mares in late gestation. In vitro studies demonstrated that this vaccine could generate cell-mediated immune response in yearlings and pregnant mares 14 days post-vaccination (Tabynov et al., 2014).

\section{Canarypox Vector Vaccines}

These vaccines are available to be administered intra-nasally, while boosters are needed at an interval of 6 months (Minke et al., 2007). These vectored vaccines produce a good amount of colostral antibodies; hence are suitable for vaccination of mares at late gestation (Daly et al., 2004). The canarypox-vectored vaccine (ProteqFlu ${ }^{\circledR}$, Merial) was chosen to vaccinate horses in the United States of America because it can evoke antibodies against HA only. As a consequence, in diagnostic ELISA, NP can be detected and discrimination between infected and vaccinated animals is possible (Daly et al., 2011; Paillot and El-Hage, 2016). Also, such vaccines can induce an immune response early and for longer duration of time against American lineage of EIV (Soboll et al., 2010). Since canarypox vectored vaccine provide longer duration of immunity, they sufficiently protect the equine population during an annual period between booster doses (Minke et al., 2007). Paillot et al. (2006a) studied the stimulation of the immune system after immunization with canarypoxbased vaccine and subsequent challenge to a nebulized aerosol of EIV. Presence of humoral response was evidenced by serum antibody level and cell mediated response that was measured by production of IFN- $\gamma$. Post-challenge, the clinical signs were reduced with increased IFN- $\gamma$ protein synthesis in vaccinated ponies. Fougerolle et al. (2016) demonstrated that all horses did 
not develop protective immunity after vaccination, resulting in an increased risk of infection and transmission. A field study was conducted to understand the poor response to primary EI immunization. During a study, 174 foals in 3 stud farms were immunized with canarypox-based vaccine and detectable antibody titer was observed after 2 nd vaccination. After 3rd vaccination, there were still $19.2 \%$ poor antibody responders. The study proved its importance in evaluating herd immunity and its role in implementing correct vaccination management. Vaccination schedule would be different for different groups of equids. Vaccinating the breeding horse in later stages of pregnancy improved the antibody titer in colostrum. Foals are vaccinated routinely at the age of 6 months when the maternal antibody level decreases. Foals from unvaccinated dams need to be vaccinated early in their life (Daly et al., 2004; Heldens et al., 2007).

\section{Modified Vaccinia Ankara Vector (MVA)}

The vector carrying HA and NP gene elicited good antibody response and also IFN- $\gamma$ and mRNA production (Breathnach et al., 2004). Two of the recombinant modified vaccinia Ankara vector constructs with HA or NP genes were found to protect the ponies from clinical disease very effectively whereas vaccine with HA gene was found better than NP gene in terms of the protective outcome (Breathnach et al., 2006).

\section{Modified Herpes Virus-1 Vectored Vaccine}

Equine herpes virus-1 vectored vaccine carrying H3 gene of EIV generated robust protective immune response against influenza (VA05 and NY-99 strains) in horses (Van de Walle et al., 2010). This vaccine was found to be significantly more effective in terms of reduced viral shedding and mild clinical symptoms during the 1997 outbreak of EIV in Australia (Paillot and El-Hage, 2016). In addition, during this outbreak in 1997, both the ISCOM matrix based and canarypox vectored EI vaccine were found to be equally efficient in preventing clinical disease (Bryant et al., 2010).

\section{Reverse Genetics Based Vaccines}

For influenza viruses including EIV, the field of reverse genetics (plasmid based) allows expression of the components of the virus involved in replication of the viral genome and transcription of gene (Nogales and Martínez-Sobrido, 2017). Live virus vaccine has been developed by reverse genetics technique employing $\mathrm{HA}$ and NA gene of eq/GA/81 wild-type (wt) virus along with the six internal protein genes of the ca A/Ann Arbor/6/60 $(\mathrm{H} 2 \mathrm{~N} 2)$ vaccine donor virus, which form the base of seasonal live attenuated influenza vaccine licensed in the market. This vaccine was found to provide protection in mice and ferrets after heterologous challenge with $\mathrm{H} 3 \mathrm{~N} 8$ (eq/Newmarket/03) wt virus (Baz et al., 2015). Another vaccine generated by reverse genetics technology is a novel reassortant of ca strain A/HK/Otar/6:2/2010 containing HA and NA genes from wildtype strain A/equine/Otar/764/2007 (H3N8) and internal genes from ca A/Hong Kong/1/68/162/35CA (H3N2) strain in the form of nasal spray. The vaccine was found safe for intranasal administration in both yearlings and pregnant mares and it replicated exclusively in upper respiratory tract and did not lead to generalized infection (Tabynov et al., 2014). Carboxyterminally truncated NS1 proteins are incapable of inhibiting type 1 IFN production by cells and are replication attenuated and thus are a vaccine candidate. Mutation at 126th amino acid position of NS1 protein, and subsequent aerosol or intranasal inoculation did not produce pyrexia with fewer clinical signs of illness and decreased virus shedding upon challenge (Chambers et al., 2009). Very recently, based on the reverse genetics vaccine approach, a temperature sensitive H3N8 EIV vaccine was developed that showed better protection both in mice and also in horse when challenged with wild type virus. As this mutant was developed by reverse genetics approach so it is possible to upgrade the vaccine strain whenever there is a mutation in the circulating virus and thus making it feasible to control the outbreak (Rodriguez et al., 2018).

\section{DNA Vaccines}

DNA vaccines delivered through gene gun have been suggested for EIV (Lunn et al., 1999; Olsen, 2000; Dhama et al., 2008). DNA vaccines carrying HA gene elicited good cell mediated and humoral immunity eliciting IgG response, but it does not provoke IgA response (Soboll et al., 2003). These DNA vaccines based on $\mathrm{H} 3 \mathrm{~N} 8$ virus are quite safe and effective in eliciting both homologous and heterologous immune response (Ault et al., 2012). For the purpose of DNA vaccination, intra-lymphatic immunotherapy (ILIT) is the recent strategy, into which HA encoding plasmid is being injected in the sub-mandibular lymph node on days 0,28 , and 98 and such vaccination induced EIV specific immune response comparable to immune response evoked after natural infection, but lower than the conventional canarypox-based EIV vaccine (Landolt et al., 2010). Intranodal immunization allows vaccine delivery directly at the site of $\mathrm{B}$ and $\mathrm{T}$ lymphocytes priming, so improved immunity is expected. However, practical feasibility of this technique in the field is questionable due to the skills required for sub-mandibular injection with the risk of inaccurate injection in lymph node (Paillot, 2014).

After reviewing all existing vaccines, Consultative Committee for Emergency Animal Diseases (CCEAD) recommended to prefer a recombinant (canarypox) vectored vaccine owing to its ability to readily evoke efficient immune response against both the American and European lineage viruses (Perkins et al., 2011). Paillot et al. (2013b) have conducted experiments to reveal the pattern of EIV shedding after infection in vaccinated horses. The information turned out to be helpful regarding changes to current quarantine requirements. The findings showed that the viral shedding detection is better in nasopharyngeal swabs than nasal swab in terms of frequency and amount of virus. Recently a study reported the use of individual nebulization for challenge infection in equines as the present method of the use of room nebulization showed decreased pathogenicity after challenge. The authors also suggested that the use of individual nebulization can decrease the use of animal numbers in a group, thus follows the 3R's principle (Replacement, Reduction, and Refinement) (Garrett et al., 2017).

Different vaccine platforms available for prevention of EIV infection are presented in Table 1, Figure 5. 

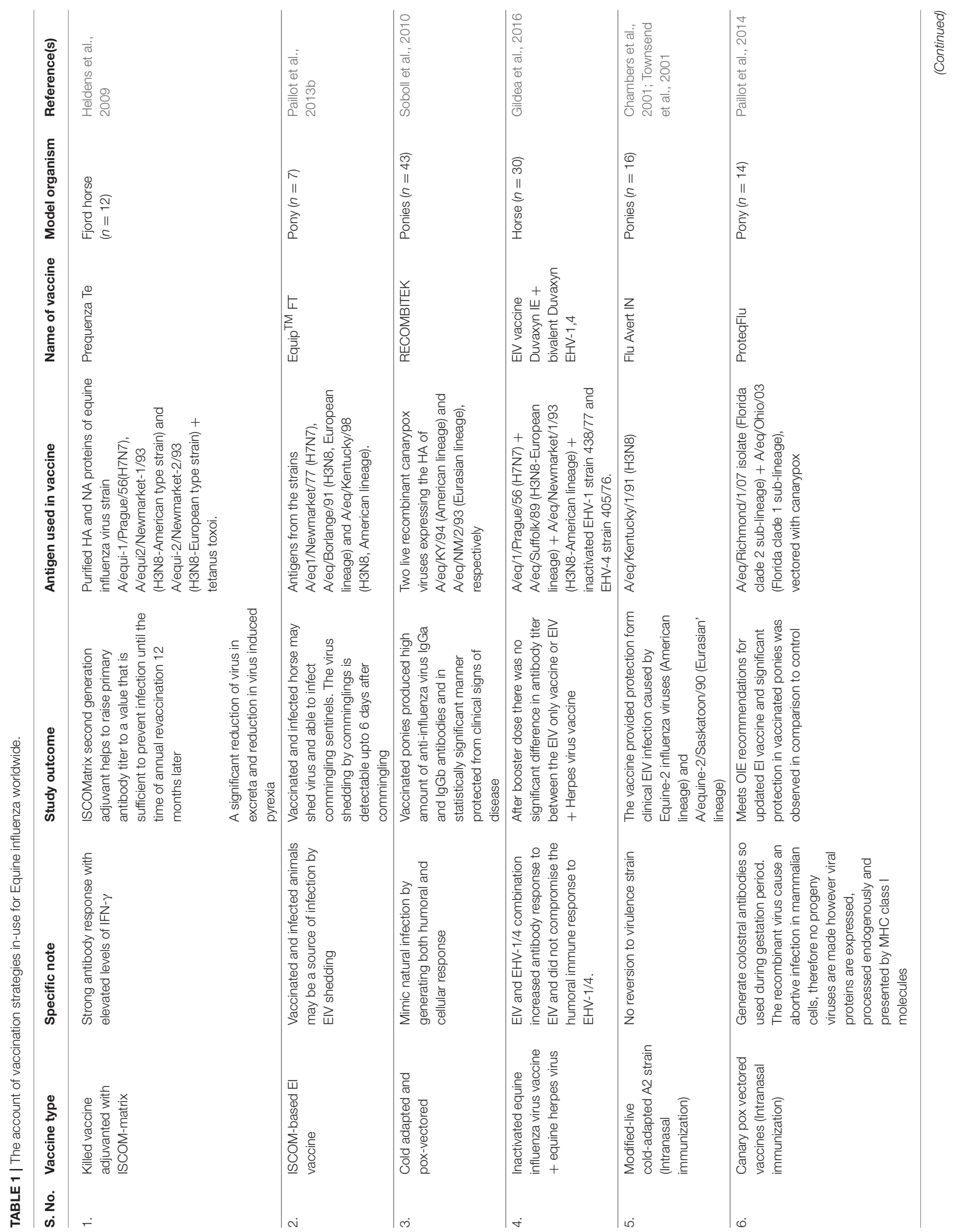


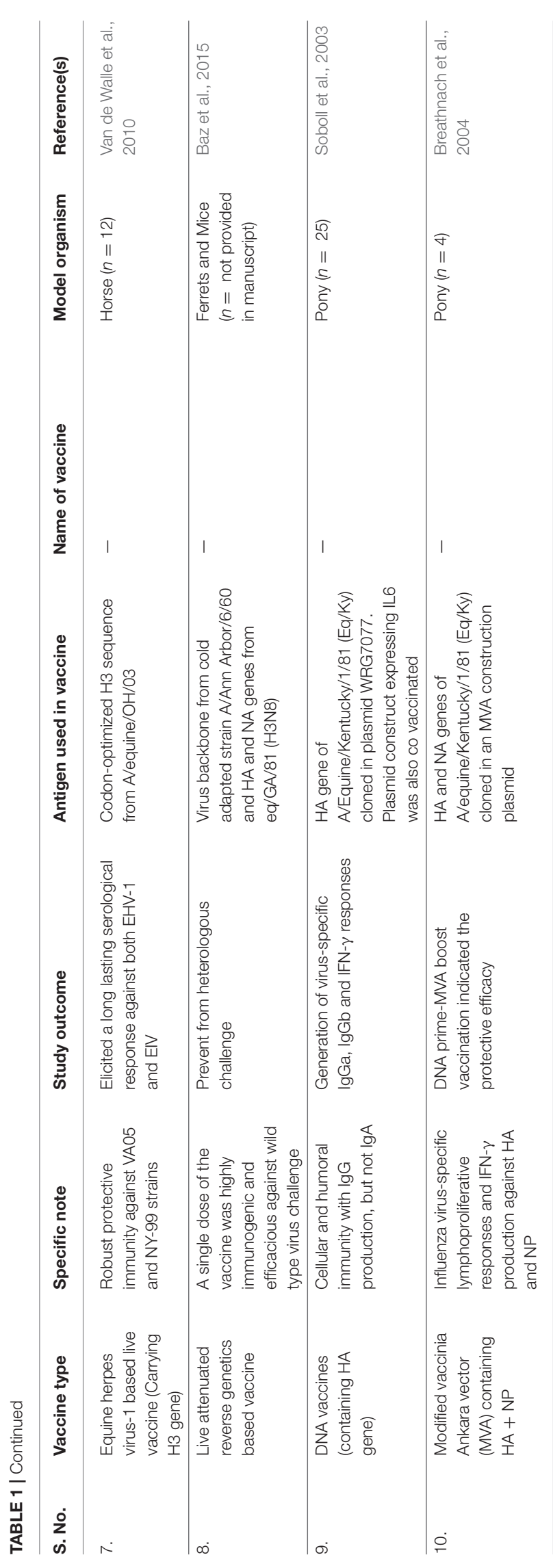

\section{Biosecurity}

Apart from vaccination, other strategies that contribute toward the control of EI include follow up of strict biosecurity measures, restricted movement and traffic, proper quarantine practices, and post vaccination surveillance programs. Importance of implementing quarantine practices strictly can be understood from the experience of the 2007 outbreak in Australia that occurred due to negligence at the time of importation of horses (Watson et al., 2011). In New Zealand, on experimental basis, InterSpread Plus (stochastic simulation model) was used in order to evaluate the efficacy of control programs. Out of various strategies evaluated for control of this disease, vaccination combined with complete movement restriction was found to be very effective in this direction in New Zealand (Rosanowski et al., 2016).

Biosecurity measures and appropriate management practices are essential for prevention and control of EI. In the event of outbreak, adoption of biosecurity measures can provide protection to horses (Schemann et al., 2012). Simple preventive measures based on personal hygiene, decontamination, and other biosecurity practices prevented spread of infection in Queensland, Australia (Frazer et al., 2011). A protocol of hygiene practices devised by a practice in which all veterinarians were involved on a daily basis in visiting infected premises, including sampling, handling of equines, treatment of clinical cases, and other common veterinary work has been described, which should be strictly followed in face of an equine influenza outbreak (Major, 2011). The implementation of strategy like high health, high performance (HHP) by OIE provides the mitigation measures for mitigating the spread of equine diseases including EI (Dominguez et al., 2015).

There are various factors and many different players responsible for prevention and control of $\mathrm{EI}$ in equine sports arena viz. vaccine producers, vaccine regulators, OIE, various government bodies in different countries, veterinary practitioners, owners, riders, trainers, etc. (Cooke, 2013). Each has a unique and important role to play in proper management of equestrian sports (Cooke, 2013). A cross sectional study was conducted on 759 Australian horse owners to determine their biosecurity practices and perceptions. It demonstrated that the young aged people, or people having no commercial involvement with horses or having no business impact of EI outbreak, were likely to have poor biosecurity compliance (Arthur and Suann, 2011).

\section{Treatment}

Mainly the managemental practices should be followed in animals affected with EIV. As a general protocol horses should be rested for the number of days/weeks equal to the number of days/weeks they had suffered fever which can aid in recovery of the respiratory epithelium (Chambers et al., 1995). Gradual work can be provided after complete rest as sudden work load can lead to chronic obstructive pulmonary disease and mycocarditis. Free air flow should be present in the stall during the resting period so that good quality oxygen supply will be available. Good hygienic food, water and dust free bedding materials should be provided at the stall (Chambers et al., 


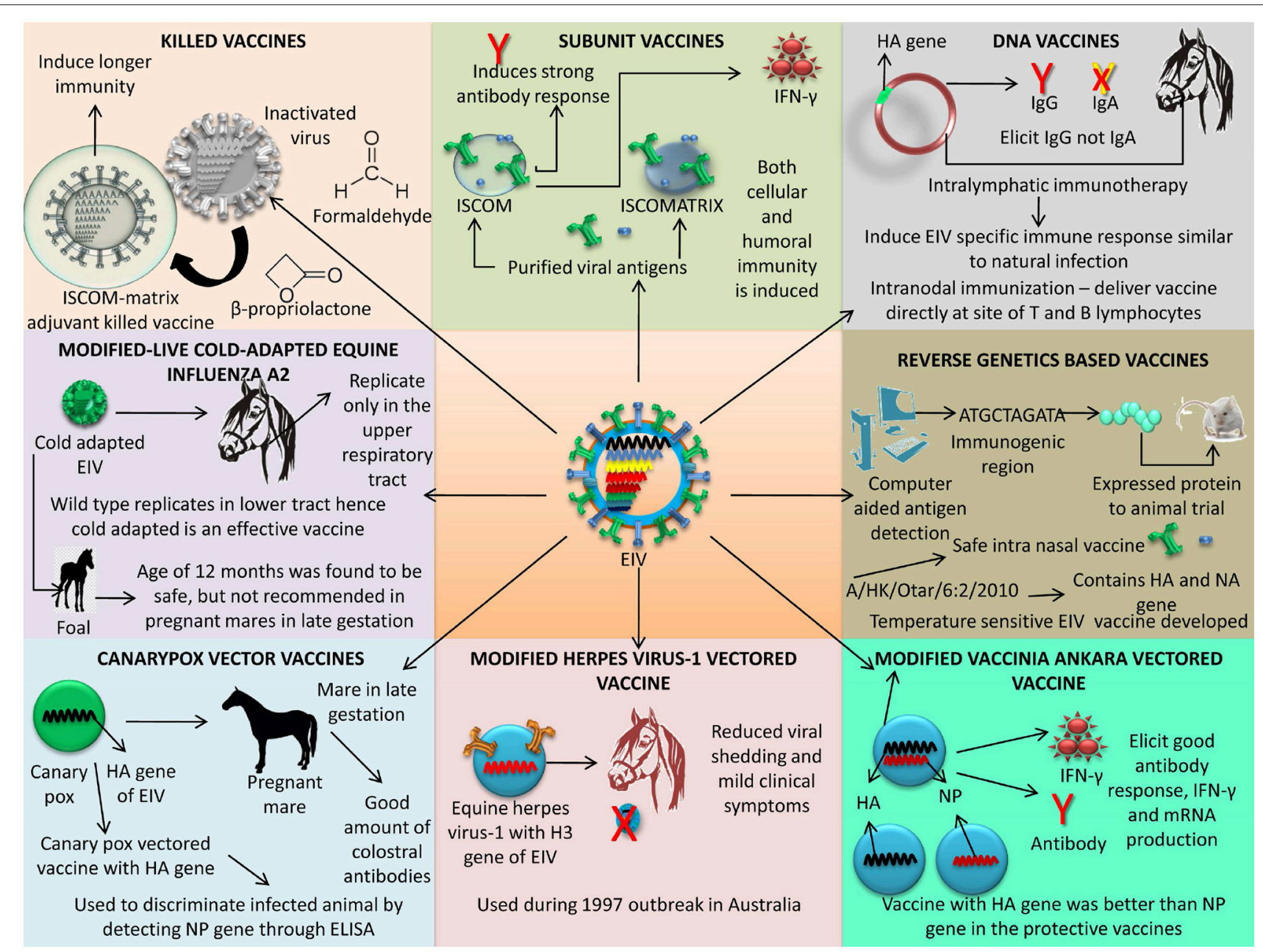

FIGURE 5 | Different vaccine platforms available for EIV. Platforms include killed vaccine, inactivated vaccine, subunit vaccine, DNA vaccine, subunit vaccine, vectored vaccine, reverse genetics-based vaccine.

1995). Though amantadine has been tried, there are no specific antiviral drugs available in the market for the treatment of EIV (Radostits et al., 2003). Treatment is mainly symptomatic and antibiotics like penicillin $G$ or trimethoprim/sulfonamide are administered to prevent from secondary bacterial infections due to Actinobacillus species and Streptococcus species. Nonsteroidal anti-inflammatory drugs like phenylbutazone, flunixin meglumine, or dipyrone can be administered to reduce fever (Wilson, 1993). Neuraminidase inhibitors such as peramivir at the early stage of infection are recommended. This drug was found to reduce virus shedding and as such limits the spread of infection from one horse to another (Yamanaka et al., 2015). Peramivir is a selective NA inhibitor having strong affinity for NA and with a slow off-rate of NA from NA-peramivir complex, providing a prolonged inhibitory effect and subsequent lower dose requirement. Single intra-venous dose of peramivir (7.8-9.3 $\mathrm{mg} / \mathrm{kg}$ of body weight) exhibited significant reduction in pyrexia, nasal discharge and cough and also in duration of viral shedding. It indicated the great potential of peramivir as treatment of equine influenza and also in line able to contain the spread of the disease (Yamanaka et al., 2012b; Cullinane and Newton, 2013).

Few of the promising anti-viral therapeutic regimens such as the use of cytokines, microRNA, si-RNA, TLRs, potent immunomodulators, nanotechnology based therapeutics, herbal and plant metabolites, and others which might have feasibilities to counter EIV needs to exploited optimally (Blecher et al., 2011; Dhama et al., 2013, 2014, 2018; Malik et al., 2013; Junquera et al., 2014; Prasad et al., 2018).

\section{CONCLUSION AND FUTURE PROSPECTS}

Equine influenza, a highly contagious respiratory disease of horses mainly caused by H3N8, is a major problem globally. There are many EIV subtypes circulating and which provide no cross-protection to other strains. Recurrent epidemics lead to reduction in horse performance. The EI outbreaks have regularly been witnessed in non-vaccinated as well as vaccinated herds 
and thus this disease has acquired a serious issue worldwide. Continuous emergence of newer strains due to mutations is yet another hindrance to the definite solution of this disease by means of vaccination. Though, no human cases in practice have been noticed yet it should be realized that under experimental settings this virus has shown the ability to infect humans with antibody induction. Of note, this virus has crossed the species barrier by causing disease in various other species (dogs, cats, camels). This should raise alarm as dogs are closely associated with humans and they may act as a mixing vessel for equine and human influenza virus facilitating emergence of new human influenza strains. It is imperative now to develop an efficient canine influenza virus vaccine and imply proper vaccination strategy in dogs to prevent such infections.

Recent advances in diagnosis and surveillance of EIV need to be exploited to their full potential to monitor the epidemiology of this virus in details and recording incidences and disease outbreaks of EI. Regular monitoring of equine population for EIV strains is mandatory to transpire the effective vaccination strategies. Better methods for assessing vaccine potency also need to be designed. A thorough understanding of disease pathogenesis will help in selecting protective epitopes for vaccine designing. Regular monitoring and surveillance of the virus can also help to update the available vaccine with the new variants that occur as due course of time owing to the evolution of the virus. Such regular updation of vaccine and

\section{REFERENCES}

Aeschbacher, S., Santschi, E., Gerber, V., Stalder, H. P., and Zanoni, R. G. (2015). Development of a real-time RT-PCR for detection of equine influenza virus. Schweiz. Arch. Tierheilkd. 157, 191-201. doi: 10.17236/sat00015

Alexander, D. J., and Brown, I. H. (2000). Recent zoonoses caused by influenza A viruses. Rev. Sci. Tech. 19, 197-225. doi: 10.20506/rst.1 9.1.1220

Alvarez, A. C., Brunck, M. E., Boyd, V., Lai, R., Virtue, E., Chen, W., et al. (2008). A broad spectrum, one-step reverse-transcription PCR amplification of the neuraminidase gene from multiple subtypes of influenza A virus. Virol. J. 5:77. doi: 10.1186/1743-422X-5-77

Alves Beuttemmüller, E., Woodward, A., Rash, A., dos Santos Ferraz, L. E., Fernandes Alfieri A., Alfieri, A. A., et al. (2016). Characterisation of the epidemic strain of H3N8 equine influenza virus responsible for outbreaks in South America in 2012. Virol J. 13:45. doi: 10.1186/s12985-016-0503-9

Arthur, R. J., and Suann, C. J. (2011). Biosecurity and vaccination strategies to minimise the effect of an equine influenza outbreak on racing and breeding. Aust. Vet. J. 89, 109-113. doi: 10.1111/j.1751-0813.2011.00764.x

Ault, A., Zajac, A. M., Kong, W. P., Gorres, J. P., Royals, M., Wei, C. J., et al. (2012). Immunogenicity and clinical protection against equine influenza by DNA vaccination of ponies. Vaccine 30, 3965-3974. doi: 10.1016/j.vaccine.2012.03.026

Back, H., Berndtsson, L. T., Gröndahl, G., Ståhl, K., Pringle, J., and Zohari, S. (2016). The first reported Florida clade 1 virus in the Nordic countries, isolated from a Swedish outbreak of equine influenza in 2011. Vet. Microbiol. 184, 1-6. doi: 10.1016/j.vetmic.2015.12.010

Balasuriya, U. B. (2014). Type A influenza virus detection from horses by realtime RT-PCR and insulated isothermal RT-PCR. Anim. Influenza Virus 1161, 393-402. doi: 10.1007/978-1-4939-0758-8_34

Balasuriya, U. B., Lee, P. Y., Tiwari, A., Skillman, A., Nam, B., Chambers, T. M., et al. (2014). Rapid detection of equine influenza virus H3N8 subtype by also testing the potency and efficacy of the updated vaccine are also mandatory to prevent and protect equine population from EIV keeping in view the evolution of the virus. It is the right time to opt various types of advancements in vaccine manufacturing and adjuvants technology for developing safe and effective EIV vaccines. Also, vaccine delivery methods can be standardized for superior quality of immune response. Further improvements in assays monitoring EIV specific antibody levels in the serum can be done, which better correlate with protection status.

\section{AUTHOR CONTRIBUTIONS}

All the authors substantially contributed to the conception, design, checking and approving final version of the manuscript, and agree to be accountable for its contents. RKS and KD initiated this review compilation. RK, KK, AM, SK, and SC updated various sections. NV reviewed Indian Scenario. MM and YM reviewed. RK designed tables and KK designed the figures. JK, RKS, RS, BT, and KD overviewed, thoroughly checked, and finally edited the whole manuscript.

\section{ACKNOWLEDGMENTS}

All the authors acknowledge and thank their respective Institutes and Universities.

insulated isothermal RT-PCR (iiRT-PCR) assay using the POCKIT ${ }^{\mathrm{TM}}$ nucleic acid analyzer. J. Virol. Methods 207, 66-72. doi: 10.1016/j.jviromet.2014.06.016

Barba, M., and Daly, J. M. (2016). The influenza NS1 protein: what do we know in equine influenza virus pathogenesis? Pathogens 5:57. doi: 10.3390/pathogens5030057

Barbic, L., Madic, J., Turk, N., and Daly, J. (2009). Vaccine failure caused an outbreak of equine influenza in Croatia. Vet. Microbiol. 133, 164-171. doi: 10.1016/j.vetmic.2008.06.009

Bayry, J. (2013). Emerging viral diseases of livestock in the developing world. Indian J. Virol. 24, 291-294. doi: 10.1007/s13337-013-0164-X

Baz, M., Paskel, M., Matsuoka, Y., Zengel, J., Cheng, X., Treanor, J. J., et al. (2015). A live attenuated equine H3N8 influenza vaccine is highly immunogenic and efficacious in mice and ferrets. J. Virol. 89, 1652-1659. doi: 10.1128/JVI.02449-14

Bengtsson, K. L. (2013). "Matrix M adjuvant technology”, in Novel Immune Potentiators and Delivery Technologies for Next Generation Vaccines (Boston, MA: Springer), 309-320.

Bera, B. C., Virmani, N., Shanmugasundaram, K., Vaid, R. K., Singh, B. K., Gulati, B. R., et al. (2013). Genetic analysis of the neuraminidase (NA) gene of equine influenza virus (H3N8) from epizootic of 2008-2009 in India. Indian J. Virol. 24, 256-264. doi: 10.1007/s13337-013-0137-0

Bernardino, P. N., Mapes, S. M., Corbin, R., and Pusterla, N. (2016). Pyrosequencing as a fast and reliable tool to determine clade affiliation for equine influenza A virus. J. Vet. Diagn. Invest. 28, 323-326. doi: $10.1177 / 1040638716638123$

Blecher, K., Nasir, A., and Friedman, A. (2011). The growing role of nanotechnology in combating infectious disease. Virulence 2, 395-401. doi: 10.4161/viru.2.5.17035

Bogerd, H. P., Skalsky, R. L., Kennedy, E. M., Furuse, Y., Whisnant, A. W., Flores, O., et al. (2014). Replication of many human viruses is refractory to inhibition by endogenous cellular microRNAs. J. Virol. 88, 8065-8076. doi: 10.1128/JVI.00985-14 
Bolfa, P., Jeon, I., Loftis, A., Leslie, T., Marchi, S., Sithole, F., et al. (2017). Detection of West Nile Virus and other common equine viruses in three locations from the Leeward Islands, West Indies. Acta Trop. 174, 24-28. doi: 10.1016/j.actatropica.2017.06.023

Boukharta, M., Azlmat, S., Elharrak, M., and Ennaji, M. M. (2015). Multiple alignment comparison of the non-structural genes of three strains of equine influenza viruses (H3N8) isolated in Morocco. BMC Res Notes 8:471. doi: 10.1186/s13104-015-1441-0

Bountouri, M., Fragkiadaki, E., Ntafis, V., Kanellos, T., and Xylouri, E. (2011). Phylogenetic and molecular characterization of equine $\mathrm{H} 3 \mathrm{~N} 8$ influenza viruses from Greece (2003 and 2007): evidence for reassortment between evolutionary lineages. Virol. J. 8:350. doi: 10.1186/1743-422X-8-350

Breathnach, C. C., Clark, H. J., Clark, R. C., Olsen, C. W., Townsend, H. G., and Lunn, D. P. (2006). Immunization with recombinant modified vaccinia Ankara (rMVA) constructs encoding the HA or NP gene protects ponies from equine influenza virus challenge. Vaccine 24, 1180-1190. doi: 10.1016/j.vaccine.2005.08.091

Breathnach, C. C., Rudersdorf, R., and Lunn, D. P. (2004). Use of recombinant modified vaccinia Ankara viral vectors for equine influenza vaccination. Vet. Immunol. Immunopathol. 98, 127-136. doi: 10.1016/j.vetimm.2003.11.004

Bryans, J. T., Doll, E. R., Wilson, J. C., and McCollum, W. H. (1966). Immunization for equine influenza. J. Am. Vet. Med. Assoc. 148, 413-417.

Bryant, N. A., Paillot, R., Rash, A. S., Medcalf, E., Montesso, F., Ross, J., et al. (2010). Comparison of two modern vaccines and previous influenza infection against challenge with an equine influenza virus from the Australian 2007 outbreak. Vet. Res. 41, 1-15. doi: 10.1051/vetres/2009067

Bryant, N. A., Rash, A. S., Russell, C. A., Ross, J., Cooke, A., Bowman, S., et al. (2009). Antigenic and genetic variations in European and North American equine influenza virus strains (H3N8) isolated from 2006 to 2007. Vet. Microbiol. 138, 41-52. doi: 10.1016/j.vetmic.2009.03.004

Bryant, N. A., Rash, A. S., Woodward, A. L., Medcalf, E., Helwegen, M., Wohlfender, F., et al. (2011). Isolation and characterisation of equine influenza viruses (H3N8) from Europe and North America from 2008 to 2009. Vet. Microbiol. 147, 19-27. doi: 10.1016/j.vetmic.2010.05.040

Burashev, Y., Strochkov, V., Sultankulova, K., Orynbayev, M., Sansyzbay, A., Sandybayev, N., et al. (2018). Complete genome sequencing of two equine influenza $\mathrm{A}(\mathrm{H} 3 \mathrm{~N} 8)$ virus strains isolated in Kazakhstan. Genome Announc. 6, e00574-e00518. doi: 10.1128/genomeA.00574-18

Burnell, F. J., Holmes, M. A., Roiko, A. H., Lowe, J. B., Heil, G. L., White, S. K., et al. (2014). Little evidence of human infection with equine influenza during the 2007 epizootic, Queensland, Australia. J. Clin. Virol. 59, 100-103. doi: 10.1016/j.jcv.2013.11.011

Chambers, T. M. (1992). Cross reactivity of existing influenza vaccine with a new strain of equine influenza virus from China. Vet. Rec. 31:388. doi: $10.1136 /$ vr.131.17.388

Chambers, T. M. (2014). "A brief introduction to equine influenza and equine influenza viruses," in Animal Influenza Virus. Methods in Molecular Biology, ed E. Spackman (New York, NY: Springer), Chapter 31, 365-370.

Chambers, T. M., and Balasuriya, U. B. R. (2016). "Equine influenza virus," in Molecular Detection of Animal Viral Pathogens, ed D. Liu (Boca Raton, FL: CRC Press), 383-392.

Chambers, T. M., Holland, R. E., Tudor, L. R., Townsend, H. G. G., Cook, A., Bogdan, J., et al. (2001). A new modified live equine influenza virus vaccine: phenotypic stability, restricted spread and efficacy against heterologous virus challenge. Equine Vet. J. 33, 630-636. doi: 10.2746/042516401776249291

Chambers, T. M., Holland, R. E. Jr., and Lai, A. C. K. (1995). Equine influenzacurrent veterinary perspectives, part 2. Equine Pract. 17, 26-30.

Chambers, T. M., Quinlivan, M., Sturgill, T., Cullinane, A., Horohov, D. W., Zamarin, D., et al. (2009). Influenza A viruses with truncated NS1 as modified live virus vaccines: pilot studies of safety and efficacy in horses. Equine Vet. J. 41, 87-92. doi: 10.2746/042516408X371937

Chambers, T. M., and Reedy, S. E. (2014a). Equine influenza diagnosis: sample collection and transport. Methods Mol. Biol. 1161, 371-377. doi: 10.1007/978-1-4939-0758-8_32

Chambers, T. M., and Reedy, S. E. (2014b). Equine influenza culture methods. Methods Mol. Biol. 1161, 403-410 doi: 10.1007/978-1-4939-0758-8_35

Chambers, T. M., and Reedy, S. E. (2014c). Equine influenza serological methods. Methods Mol. Biol. 1161, 411-422. doi: 10.1007/978-1-4939-0758-8_36
Chambers, T. M., Shortridge, K. F., Li, P. H., Powell, D. G., and Watkins, K. L. (1994). Rapid diagnosis of equine influenza by the directigen FLU-A enzyme immunoassay. Vet. Rec. 135, 275-279. doi: 10.1136/vr.135.12.275

Chien, C. Y., Xu, Y., Xiao, R., Aramini, J. M., Sahasrabudhe, P. V., Krug, R. M., et al. (2004). Biophysical characterization of the complex between doublestranded RNA and the N-terminal domain of the NS1 protein from influenza A virus: evidence for a novel RNA-binding mode. Biochemistry 43, 1950-1962. doi: 10.1021/bi030176o

Collins, P. J., Vachieri, S. G., Haire, L. F., Ogrodowicz, R. W., Martin, S. R., Walker, P. A., et al. (2014). Recent evolution of equine influenza and the origin of canine influenza. Proc. Natl. Acad. Sci. U.S.A. 111, 11175-11180. doi: $10.1073 /$ pnas. 1406606111

Cook, R. F., Sinclair, R., and Mumford, J. A. (1988). Detection of influenza nucleoprotein antigen in nasal secretions from horses infected with A/equine influenza (H3N8) viruses. J. Virol. Methods 20, 1-12. doi: 10.1016/0166-0934(88)90034-1

Cooke, G. (2013). Vaccination for equine influenza: the sports regulator's viewpoint. Equine Vet. J. 45, 770-771. doi: 10.1111/evj.12151

Couch, R. B., Douglas, R. G., Rossen, R., and Kasel, J. (1969). "Role of secretory antibody in influenza," in The Secretory Immune System (Washington, DC: U.S. Dept. of Public Health), 93-112.

Cowled, B., Ward, M. P., Hamilton, S., and Garner, G. (2009). The equine influenza epidemic in Australia: Spatial and temporal descriptive analyses of a large propagating epidemic. Prev. Vet. Med. 92, 60-70. doi: 10.1016/j.prevetmed.2009.08.006

Crawford, P. C., Dubovi, E. J., Castleman, W. L., Stephenson, I., Gibbs, E. P., Chen, L., et al. (2005). Transmission of equine influenza virus to dogs. Science 310, 482-485. doi: 10.1126/science.1117950

Crispe, E., Finlaison, D. S., Hurt, A. C., and Kirkland, P. D. (2011). Infection of dogs with equine influenza virus: evidence for transmission from horses during the Australian outbreak. Aust. Vet. J. 89, 27-28. doi: 10.1111/j.1751-0813.2011.00734.x

Crouch, C. F., Daly, J., Hannant, D., Wilkins, J., and Francis, M. J. (2004). Immune responses and protective efficacy in ponies immunized with and equine influenza ISCOM vaccine containing an 'American lineage' H3N8 virus. Vaccine 23, 418-425. doi: 10.1016/j.vaccine.2004.01.074

Crouch, C. F., Daly, J., Henley, W., Hannant, D., Wilkins, J., and Francis, M. J. (2005). The use of a systemic prime/mucosal boost strategy with an equine influenza ISCOM vaccine to induce protective immunity in horses. Vet. Immunol. Immunopathol. 108, 345-355. doi: 10.1016/j.vetimm.2005.06.009

Cullinane, A., Elton, D., and Mumford, J. (2010). Equine influenzasurveillance and control. Influenza Other Respir. Viruses 4, 339-344. doi: 10.1111/j.1750-2659.2010.00176.x

Cullinane, A., and Newton, J. R. (2013). Equine influenza-a global perspective. Vet. Microbiol. 167, 205-214. doi: 10.1016/j.vetmic.2013.03.029

Cullinane, A. A., Barr, B., Bernard, W., Duncan, J. L., Mulcahy, G., Smith, M., et al. (2006). "Infectious diseases (chapter 1): equine influenza," in The Equine Manual. 2nd Edn, eds A. J. Higgins and J. R. Snyder (Philadelphia, PA: Elsevier Saunders), 13-18.

Daly, J. M., Blunden, A. S., Macrae, S., Miller, J., Bowman, S. J., Kolodziejek, J., et al. (2008). Transmission of equine influenza virus to English foxhounds. Emerg. Infect. Dis. 14, 461-464. doi: 10.3201/eid1403.070643

Daly, J. M., Lai, A. C., Binns, M. M., Chambers, T. M., Barrandeguy, M., and Mumford, J. A. (1996). Antigenic and genetic evolution of equine H3N8 influenza A viruses. J. Gen. Virol. 77, 661-671. doi: 10.1099/0022-1317-77-4-661

Daly, J. M., MacRae, S., Newton, J. R., Wattrang, E., and Elton, D. M. (2011). Equine influenza: a review of an unpredictable virus. Vet. J. 189, 7-14. doi: 10.1016/j.tvjl.2010.06.026

Daly, J. M., and Murcia, P. R. (2018). Strategic implementation of vaccines for control of equine influenza. Equine Vet. J. 50, 153-154. doi: 10.1111/evj. 12794

Daly, J. M., Newton, J. R., and Mumford, J. A. (2004). Current perspectives on control of equine influenza. Vet. Res. 35, 411-423. doi: 10.1051/vetres:2004023

Daly, J. M., Whitwell, K. E., Millera, J., Dowd, G., Cardwell, J. M., and Smith, K. C. (2006). Investigation of equine influenza cases exhibiting neurological disease: coincidence or association? J. Comp. Pathol. 134, 231-235. doi: 10.1016/j.jcpa.2005.09.001 
Damiani, A. M., Scicluna, M. T., Ciabatti, I., Cardeti, G., Sala, M., Vulcano, G., et al. (2008). Genetic characterization of equine influenza viruses isolated in Italy between 1999 and 2005. Virus Res. 131, 100-105. doi: 10.1016/j.virusres.2007.08.001

Dhama, K., Chakraborty, S., Tiwari, R., Verma, A. K., Saminathan, M., Amarpal, M., et al. (2014). A concept paper on novel technologies boosting production and safeguarding health of humans and animals. Res. Opin. Anim. Vet. Sci. 4, 353-370.

Dhama, K., Chakraborty, S., Wani, M. Y., Verma, A. K., Deb, R., et al. (2013). Novel and emerging therapies safeguarding health of humans and their companion animals: a review. Pak. J. Biol. Sci. 16, 101-111. doi: 10.3923/pjbs.2013.101.111

Dhama, K., Karthik, K., Khandia, R., Munjal, A., Tiwari, R., Rana, R., et al. (2018). Medicinal and therapeutic potential of herbs and plant metabolites/extracts countering viral pathogens-current knowledge and future prospects. Curr. Drug Metab. 19, 236-263. doi: 10.2174/1389200219666180129145252

Dhama, K., Mahendran, M., Gupta, P. K., and Rai, A. (2008). DNA Vaccines and their applications in veterinary practice: current perspectives. Vet. Res. Commun. 32, 341-356. doi: 10.1007/s11259-008-9040-3

Diallo, I., Read, A. J., and Kirkland, P. D. (2011). Positive results in a real-time PCR for type A influenza associated with the use of an inactivated vaccine. Aust. Vet. J. 89, 145-146. doi: 10.1111/j.1751-0813.2011.00746.x

Diaz-Mendez, A., Viel, L., Hewson, J., Doig, P., Carman, S., Chambers, T., et al. (2010). Surveillance of equine respiratory viruses in Ontario. Can. J. Vet. Res. 74, 271-278

Dominguez, M., Münstermann, S., Murray, G., and Timoney, P. (2015). Highhealth, high-performance' horses: risk mitigation strategies for OIE-listed diseases. Rev. Sci. Tech. 34, 837-848. doi: 10.20506/rst.34.3.2399

Donofrio, J. C., Coonrod, J. D., and Chambers, T. M. (1994). Diagnosis of equine influenza by the polymerase chain reaction. J. Vet. Diagn. Invest. 6, 39-43. doi: 10.1177/104063879400600108

Easterday, B. C., Hinshaw, V. S., and Halvorson, D. A. (1997). "Influenza," in Diseases of Poultry, 10th Edn., eds. B. W. Calnek, H. J. Barnes, C. W. Beard, L. R. McDougald, and Y. M. Saif (London: Mosby-Wolfe), 583-605.

Edelman, R. (2000). "An overview of adjuvant use," in Vaccine Adjuvants: Preparation Methods and Research Protocols, Vol. 42 (Totowa, NJ: Humana Press Inc.), 1-27.

Elbadry, M. A., Merrill, M. M., Ma, M. M., Ma, M. J., Lu, J. H., Cao, W. C., et al. (2014). China's great wall, Israel's bar lev line, and passive infectious disease surveillance. Mil. Med. Res. 1, 15. doi: 10.1186/2054-9369-1-15

Elton, D., Bruce, E. A., Bryant, N., Wise, H. M., MacRae, S., Rash, A., et al. (2013). The genetics of virus particle shape in equine influenza A virus. Influenza Other Respir. Viruses 7, 81-89. doi: 10.1111/irv.12197

Elton, D., and Bryant, N. (2011). Facing the threat of equine influenza. Equine Vet. J. 43, 250-258. doi: 10.1111/j.2042-3306.2010.00357.x

Elton, D., and Cullinane, A. (2013). Equine influenza: antigenic drift and implications for vaccines. Equine Vet. J. 45, 768-769. doi: 10.1111/evj.12148

Favaro, P. F., Fernandes, W. R., Reischak, D., Brandão, P. E., Silva, S. O. S., and Richtzenhain, L. J. (2018). Evolution of equine influenza viruses (H3N8) during a Brazilian outbreak, 2015. Braz. J. Microbiol. 49, 336-346. doi: 10.1016/j.bjm.2017.07.003

Feng, K. H., Gonzalez, G., Deng, L., Yu, H.,Tse, V. L., Huang, L., et al. (2015). Equine and canine influenza $\mathrm{H} 3 \mathrm{~N} 8$ viruses show minimal biological differences despite phylogenetic divergence. J. Virol. 89, 6860-6873. doi: 10.1128/JVI.00521-15

Feng, K. H., Sun, M., Iketani, S., Holmes, E. C., and Parrish, C. R. (2016). Comparing the functions of equine and canine influenza H3N8 virus PA-X proteins: suppression of reporter gene expression and modulation of global host gene expression. Virology 496, 138-146. doi: 10.1016/j.virol.2016.06.001

Ferguson, L., Olivier, A. K., Genova, S., Epperson, W. B., Smith, D. R., Schneider, L., et al. (2016). Pathogenesis of influenza D virus in cattle. J. Virol. 90, 5636-5642. doi: 10.1128/JVI.03122-15

Foord, A. J., Selleck, P., Colling, A., Klippel, J., Middleton, D., and Heine, H. G. (2009). Real-time RT-PCR for detection of equine influenza and evaluation using samples from horses infected with A/equine/Sydney/2007 (H3N8). Vet. Microbiol. 137, 1-9. doi: 10.1016/j.vetmic.2008.12.006

Fougerolle, S., Legrand, L., Garrett, D., Birand, I., Foursin, M., D'Ablon, X., et al. (2016). Influential factors inducing suboptimal humoral response to vector-based influenza immunisation in thoroughbred foals. Vaccine 34, 3787-3795. doi: 10.1016/j.vaccine.2016 05.068

Fougerolle, S., Legrand, L., Lecouturier, F., Sailleau, C., Paillot, R., Hans, A., et al. (2017). Genetic evolution of equine influenza virus strains (H3N8) isolated in France from 1967 to 2015 and the implications of several potential pathogenic factors. Virology 505, 210-217. doi: 10.1016/j.virol.2017.02.003

Frazer, J. L., Perkins, N. R., and Pitt, D. (2011). Role of personal decontamination in preventing the spread of equine influenza. Aust. Vet. J. 89, 120-124. doi: 10.1111/j.1751-0813.2011.00763.x

Gahan, J., Garvey, M., Gildea, S., Gür, E., Kagankaya, A., and Cullinane, A. (2017). Whole-genome sequencing and antigenic analysis of the first equine influenza virus identified in Turkey. Influenza Other Respir. Viruses 12, 374-385. doi: 10.1111/irv.12485

Gaíva e Silva, L., Borges, A. M., Villalobos, E. M., Lara Mdo, C., Cunha, E. M., de Oliveira, A. C., et al. (2014). Prevalence of antibodies against influenza virus in non-vaccinated equines from the Brazilian Pantanal. Rev. Inst. Med. Trop. Sao Paulo 56, 487-492. doi: 10.1590/S0036-46652014000600006

Galvin, P., Gildea, S., Arkins, S., Walsh, C., and Cullinane, A. (2013). The evaluation of a nucleoprotein ELISA for the detection of equine influenza antibodies and the differentiation of infected from vaccinated horses (DIVA). Influenza Other Respir. Viruses 7, 73-80. doi: 10.1111/irv.12195

Galvin, P., Gildea, S., Nelly, M., Quinlivan, M., Arkins, S., Walsh, C., et al. (2014). The evaluation of three diagnostic tests for the detection of equine influenza nucleoprotein in nasal swabs. Influenza Other Respir. Viruses 8, 376-383. doi: 10.1111/irv.12235

Gamoh, K., and Nakamura, S. (2017). Update of inactivated equine influenza vaccine strain in Japan. J. Vet. Med. Sci. 79, 649-653. doi: 10.1292/jvms.16-0558

Garrett, D., Montesso, F., Fougerolle, S., Lopez-Alvarez, M. R., Birand, I., De Bock, M., et al. (2017). Refinement of the equine influenza model in the natural host: a meta-analysis to determine the benefits of individual nebulisation for experimental infection and vaccine evaluation in the face of decreased strain pathogenicity. Vet. Microbiol. 211, 150-159. doi: 10.1016/j.vetmic.2017.10.010

Gerber, H. (1970). "Clinical features, sequelae and epidemiology of equine influenza," in Proceedings of the 2nd International Conference on Equine Infectious Diseases, Paris, 1969, New York, 1970, ed J. T. Bryans (Basel: Karger), 63-80.

Gibbs, E. P., and Anderson, T. C. (2010). Equine and canine influenza: a review of current events. Anim. Health Res. Rev. 11, 43-51. doi: $10.1017 /$ S1466252310000046

Gildea, S., Arkins, S., and Cullinane, A. (2010). A comparative antibody study of the potential susceptibility of thoroughbred and non-thoroughbred horse populations in Ireland to equine influenza virus. Influenza Other Respir. Viruses 4, 363-372. doi: 10.1111/j.1750-2659.2010.00163.x

Gildea, S., Arkins, S., and Cullinane, A. (2011). Management and environmental factors involved in equine influenza outbreaks in Ireland 2007-2010. Equine Vet. J. 43, 608-617. doi: 10.1111/j.2042-3306.2010.00333.x

Gildea, S., Garvey, M., Lyons, P., Lyons, R., Gahan, J., Walsh, C., et al. (2018). Multifocal equine influenza outbreak with vaccination breakdown in thoroughbred racehorses. Pathogens 7:E43. doi: 10.3390/pathogens7020043.

Gildea, S., Quinlivan, M., Arkins, S., and Cullinane, A. (2012). The molecular epidemiology of equine influenza in Ireland from 20072010 and its international significance. Equine Vet. J. 44, 387-392. doi: 10.1111/j.2042-3306.2011.00472.x

Gildea, S., Sanchez Higgins, M. J., Johnson, G., Walsh, C., and Cullinane, A. (2016). Concurrent vaccination against equine influenza and equine herpes virus-a practical approach. Influenza Other Respir. Viruses 10, 433-437. doi: 10.1111/irv.12396

Gonzalez, G., Marshall, J. F., Morrell, J., Robb, D., McCauley, J. W., Perez, D. R., et al. (2014). Infection and pathogenesis of canine, equine, and human influenza viruses in canine tracheas. J. Virol. 88, 9208-9219. doi: 10.1128/JVI.008 $87-14$

Gora, I. M., Kwasnik, M., Zmudzinski, J. F., and Rozek, W. (2017). Chorioallantoic membranes of embryonated chicken eggs as an alternative system for isolation of equine influenza virus. Virol. J. 14, 120. doi: 10.1186/s12985-017-0 788-3

Guo, Y., Wang, M., Kawaoka Y, Gorman O, Ito T, Saito T. (1992). Characterization of new avian like influenza A virus from horses in China. Virology 188:245. doi: 10.1016/0042-6822(92)90754-D 
Gupta, A. K., Anita, A., and Vandanajay, B. (2003). Detection of equine influenza viral genome by RT-PCR and RNA-DNA hybridization. Indian J. Biotech. 2, 214-219.

Hale, B. G., Randall, R. E., Ortín, J., and Jackson, D. (2008). The multifunctional NS1 protein of influenza A viruses. J. Gen. Virol. 89, 2359-2376. doi: 10.1099/vir.0.2008/004606-0

Hayward, J. J., Dubovi, E. J., Scarlett, J. M., Janeczko, S., Holmes, E. C., and Parrish, C. R. (2010). Microevolution of canine influenza virus in shelters and its molecular epidemiology in the United States. J. Virol. 84, 12636-12645. doi: 10.1128/JVI.01350-10

Heldens, J. G., Pouwels, H. G., Derks, C. G., Van de Zande, S. M., and Hoeijmakers, M. J. (2009). The first safe inactivated equine influenza vaccine formulation adjuvanted with ISCOM-Matrix that closes the immunity gap. Vaccine 27, 5530-5537. doi: 10.1016/j.vaccine.2009.06.085

Heldens, J. G., Pouwels, H. G., and van Loon, A. A. (2004). Efficacy and duration of immunity of a combined equine influenza and equine herpesvirus vaccine against challenge with an American-like equine influenza virus (A/equi2/Kentucky/95). Vet. J. 167, 150-157. doi: 10.1016/S1090-0233(03)00028-5

Heldens, J. G., van Loon, A. A., and van de Zande, S. (2007). Is there a benefit from an early booster vaccination in the control of equine influenza? Vet. J. 174, 592-598. doi: 10.1016/j.tvjl.2007.03.004

Hemann, E. A., Kang, S. M., and Legge, K. L. (2013). Protective CD8 T cell-mediated immunity against influenza A virus infection following influenza virus-like particle vaccination. J. Immunol. 191, 2486-2494. doi: 10.4049/jimmunol.1300954

Hinshaw, V. S., Olsen, C. W., Dybdahl-Sissoko, N., and Evans, D. (1994). Apoptosis: a mechanism of cell killing by influenza A and B viruses. J. Virol. $68,3667-3673$.

Holland, R. E. (2003). Equine Influenza. Art. No: 4584. Available online at: www. thehorse.com

Horspool, L. J., and King, A. (2013). Equine influenza vaccines in Europe: a view from the animal health industry. Equine Vet. J. 45, 774-775. doi: 10.1111 /evj.12171

Hughes, J., Allen, R. C., Baguelin, M., Hampson, K., Baillie, G. J., Elton, D., et al. (2012). Transmission of equine influenza virus during an outbreak is characterized by frequent mixed infections and loose transmission bottlenecks. PLoS Pathog. 8:e1003081. doi: 10.1371/journal.ppat.1003081

Ibañez, L. I., Caldevilla, C. A., Paredes Rojas, Y., and Mattion, N. (2018). Genetic and subunit vaccines based on the stem domain of the equine influenza hemagglutinin provide homosubtypic protection against heterologous strains. Vaccine 36, 1592-1598. doi: 10.1016/j.vaccine.2018.02.019

Ito, M., Nagai, M., Hayakawa, Y., Komae, H., Murakami, N., Yotsuya, S., et al. (2008). Genetic analyses of an H3N8 influenza virus isolate, causative strain of the outbreak of equine influenza at the Kanazawa Racecourse in Japan in 2007. J. Vet. Med. Sci. 70, 899-906. doi: 10.1292/jvms.70.899

Ito, T., and Kawaoka, Y. (2000). Host-range barrier of Influenza A viruses. Vet. Microbiol. 74, 71-75. doi: 10.1016/S0378-1135(00)00167-X

Jagger, B. W., Wise, H. M., Kash, J. C., Walters, K. A., Wills, N. M., Xiao, Y. L., et al. (2012). An overlapping protein-coding region in influenza A virus segment 3 modulates the host response. Science 337, 199-204. doi: 10.1126/science.1222213

Joseph, U., Su, Y. C., Vijaykrishna, D., and Smith, G. J. (2017). The ecology and adaptive evolution of influenza A interspecies transmission. Influenza Other Respir. Viruses 11, 74-84. doi: 10.1111/irv.12412

Junquera, E. C., Mateos-Hernández, L., de la Fuente, J., and de la Lastra, J. M. (2014). Recent advances in the development of anti-Infective prophylactic and/or therapeutic agents based on toll-like receptor (TLRs). Recent Pat. Antiinfect. Drug Discov. 9, 14-24. doi: 10.2174/1574891X09666140616164918

Kapoor, S., and Dhama, K. (2014). Insight into Influenza Viruses of Animals and Humans. Cham: Springer International Publishing, A. G., 1-222.

Karamendin, K., Kydyrmanov, A., Kasymbekov, Y., Khan, E., Daulbayeva, K., Asanova, S., et al. (2014). Continuing evolution of equine influenza virus in Central Asia, 2007-2012. Arch. Virol. 159, 2321-2327. doi: 10.1007/s00705-014-2078-3

Kawaoka, Y., Bean, W. J., and Webster, R. G. (1989). Evolution of the hemagglutinin of equine H3 influenza viruses. Virology 169, 283-292. doi: 10.1016/0042-6822(89)90153-0
Khan, A., Mushtaq, M. H., Ahmad, M. U. D., Nazir, J., Farooqi, S. H., and Khan, A. (2017). Molecular epidemiology of a novel re-assorted epidemic strain of equine influenza virus in Pakistan in 2015-16. Virus Res. 240, 56-63. doi: 10.1016/j.virusres.2017.07.022

Khurelbaatar, N., Krueger, W. S., Heil, G. L., Darmaa, B., Ulziimaa, D., Tserennorov, D., et al. (2013). Sparse evidence for equine or avian influenza virus infections among Mongolian adults with animal exposures. Influenza Other Respir. Viruses 7, 1246-1250. doi: 10.1111/irv.12148

Khurelbaatar, N., Krueger, W. S., Heil, G. L., Darmaa, B., Ulziimaa, D., Tserennorov, D., et al. (2014). Little evidence of avian or equine influenza virus infection among a cohort of Mongolian adults with animal exposures, 2010-2011. PLoS ONE 9:e85616. doi: 10.1371/journal.pone.0085616

Kinsley, R., Scott, S. D., and Daly, J. M. (2016). Controlling equine influenza: traditional to next generation serological assays. Vet. Microbiol. 187, 15-20. doi: 10.1016/j.vetmic.2016.03.006

Kirkland, P. D., and Delbridge, G. (2011). Use of a blocking ELISA for antibodies to equine influenza virus as a test to distinguish between naturally infected and vaccinated horses: proof of concept studies. Aust. Vet. J. 89, 45-46. doi: 10.1111/j.1751-0813.2011.00743.x

Kirkland, P. D., Finlaison, D. S., Crispe, E., and Hurt, A. C. (2010). Influenza virus transmission from horses to dogs, Australia. Emerg. Infect. Dis. 16, 699-702. doi: 10.3201/eid1604.091489

Koel, B. F., Burke, D. F., Bestebroer, T. M., van der Vliet, S., Zondag, G. C., Vervaet, G., et al. (2013). Substitutions near the receptor binding site determine major antigenic change during influenza virus evolution. Science 342, 976-979. doi: $10.1126 /$ science. 1244730

Krumbholz, A., Philipps, A., Oehring, H., Schwarzer, K., Eitner, A., Wutzler, P., et al. (2011). Current knowledge on PB1-F2 of influenza A viruses. Med. Microbiol. Immunol. 200, 69-75. doi: 10.1007/s00430-010-0176-8

Kumar, N., Bera, B. C., Greenbaum, B. D., Bhatia, S., Sood, R., Selvaraj, P., et al. (2016). Revelation of influencing factors in overall codon usage bias of equine influenza viruses. PLoS ONE 11:e0154376. doi: 10.1371/journal.pone.0 154376

Kwasnik, M., Gora, I. M., Rola, J., Zmudzinski, J. F., and Rozek, W. (2016). NSgene based phylogenetic analysis of equine influenza viruses isolated in Poland. Vet. Microbiol. 182, 95-101. doi: 10.1016/j.vetmic.2015.10.028

Laabassi, F. (2016). "Epidemiology of equine influenza viruses," in Epidemiology of Communicable and Non-Communicable Diseases-Attributes of Lifestyle and Nature on Humankind, ed F. Kasenga (InTech). Available online at: https:// www.intechopen.com/books/epidemiology-of-communicable-and-noncommunicable-diseases-attributes-of-lifestyle-and-nature-on-humankind/ epidemiology-of-equine-influenza-viruses

Lai, A. C., Chambers, T. M., Holland, R. E. Jr., Morley, P. S., Haines, D. M., Townsend, H. G., et al. (2001). Diverged evolution of recent equine-2 influenza (H3N8) viruses in the western hemisphere. Arch. Virol. 146, 1063-1074. doi: $10.1007 / \mathrm{s} 007050170106$

Lamb, R. A., and Lai, C. J. (1980). Sequence of interrupted and uninterrupted mRNAs and cloned DNA coding for the two overlapping nonstructural proteins of influenza virus. Cell 21, 475-485. doi: 10.1016/0092-8674(80)90484-5

Landolt, G. A. (2014). Equine influenza virus. Vet. Clin. N. Am. Equine Pract. 30, 507-522. doi: 10.1016/j.cveq.2014.08.003

Landolt, G. A., Hussey, S. B., Kreutzer, K., Quintana, A., Lunn, D. P. (2010). Lowdose DNA vaccination into the submandibular lymph nodes in ponies. Vet. Rec. 167, 302-303. doi: 10.1136/vr.c3891

Landolt, G. A., Townsend, H. G. G., and Lunn, D. P. (2007). "Equine influenza infection," in Equine Infectious Diseases, eds D. C. Sellon, and M. T. Long (Philadelphia, PA: Saunders; Elsevier Inc.), Chapter 12, 124-134.

Larson, K. R., Heil, G. L., Chambers, T. M., Capuanod, A., White, S. K., and Gray, G. C. (2015). Serological evidence of equine influenza infections among persons with horse exposure, Iowa. J. Clin. Virol. 67, 78-83. doi: 10.1016/j.jcv.2015.04.009

Law, J. (1874). "Influenza in horses," in Report of the Commissioner of Agriculture for the Year 1872, ed Commission of Agriculture (Washington, DC: Government Printing Office), 203-248.

Lee, E., Kim, E. J., Shin, Y. K., and Song, J. Y. (2016). Design and testing of multiplex RT-PCR primers for the rapid detection of influenza A virus genomic 
segments: application to equine influenza virus. J. Virol. Methods 228, 114-122. doi: 10.1016/j.jviromet.2015.11.012

Lee, J., Park, J. H., and Min, J. Y. (2017). A naturally truncated NS1 protein of influenza A virus impairs its interferon-antagonizing activity and thereby confers attenuation in vitro. Arch. Virol. 162, 13-21. doi: 10.1007/s00705-016-2966-9

Legrand, L. J., Pitel, P. H., Cullinane, A. A., Fortier, G. D., and Pronost, S. L. (2015). Genetic evolution of equine influenza strains isolated in France from 2005 to 2010. Equine Vet. J. 47, 207-211. doi: 10.1111/evj.12244

Lewis, N. S., Anderson, T. K., Kitikoon, P., Skepner, E., Burke, D. F., and Vincent, A. L. (2014). Substitutions near the hemagglutinin receptor-binding site determine the antigenic evolution of influenza A H3N2 viruses in U.S. Swine. J. Virol. 88, 4752-4763. doi: 10.1128/JVI.03805-13

Lewis, N. S., Daly, J. M., Russell, C. A., Horton, D. L., Skepner, E., Bryant, N. A., et al. (2011). Antigenic and genetic evolution of equine influenza A (H3N8) virus from 1968 to 2007. J. Virol. 85, 12742-12749. doi: 10.1128/JVI.05319-11

Lin, C., Holland, R. E. Jr., Donofrio, J. C., McCoy, M. H., Tudor, L. R., Chambers, T. M. (2002). Caspase activation in equine influenza virus induced apoptotic cell death. Vet. Microbiol. 84, 357-365. doi: 10.1016/S0378-1135(01)00 468-0

Livesay, G. J., O’neill, T., Hannant, D., Yadav, M. P., and Mumford, J. A. (1993). The outbreak of equine influenza (H3N8) in the United Kingdom in 1989; diagnostic use of an antigen capture ELISA. Vet. Rec. 133, 515-519.

Lu, Z., Chambers, T. M., Boliar, S., Branscum, A. J., Sturgill, T. L., Timoney, P. J., et al. (2009). Development and evaluation of one-step TaqMan real-time reverse transcription-PCR assays targeting nucleoprotein, matrix, and hemagglutinin genes of equine influenza virus. J. Clin. Microbiol. 47, 3907-3913. doi: 10.1128/JCM.00598-09

Lunn, D. P., Soboll, G., Schram, B. R., Quass, J., McGregor, M. W., Drape, R. J., et al. (1999). Antibody responses to DNA vaccination of horses using the influenza virus hemagglutinin gene. Vaccine 17, 2245-2258. doi: 10.1016/S0264-410X(98)00496-4

Major, D. A. (2011). Hygiene practices to prevent the spread of equine influenza by humans. Aust. Vet. J. 89, 124-125. doi: 10.1111/j.1751-0813.2011.00765.x

Malik, Y. S., Sharma, K., Jeena, L. M., Kumar, N., Sircar, S., Rajak, K. K., et al. (2013). Toll-like receptors: the innate immune receptors with ingenious antiviral paradigm. South Asian J. Exp. Biol. 3, 207-213.

Manjrekar, S. L., Gorhe, D. S., and Paranjape, V. L. (1965). Observations on the coughing outbreak "Newmarket cough" in the race horses in Bombay. Indian Vet. J. 42, 461-464.

Mathew, T., Dhama, K., Pawaiya, R. V. S., and Mahendran, M. (2010). "Equine influenza," in Advances in Medical and Veterinary Virology, Immunology, and Epidemiology-Vol. 7: Tropical Viral Diseases of Large Domestic Animals-Part 1, ed T. Mathew (West Orange, NJ; United Kingdom: Thajema Publishers; Xlibris Corporation), Chapter 133-151.

Mathew, T., Mahendran, M., and Dhama, K. (2006). "Equine influenza (Chapter VII)," in Advances in Medical \& Veterinary Virology, Immunology and Epidemiology, Vol. 6: Influenza and it's Public Health Significance, eds: T. M. Mathew and T. Mathew (West Orange, NJ: Thajema Publishers), 112-129.

McAuley, J. L., Kedzierska, K., Brown, L. E., and Shanks, G. D. (2015). Host immunological factors enhancing mortality of young adults during the 1918 influenza pandemic. Front. Immunol. 6:419. doi: 10.3389/fimmu.2015. 00419

McKinstry, K. K., Dutton, R. W., Swain, S. L., et al. (2013). Memory CD4 T cellmediated immunity against influenza A virus: more than a little helpful. Arch. Immunol. Ther. Exp. 61, 341-353. doi: 10.1007/s00005-013-0236-z

Meeusen, E. N., Walker, M. J., Peters, A., Pastoret, P. P., and Jungersen, G. (2007). Current status of veterinary vaccines. Clin. Microbiol. Rev. 20, 3489-3510. doi: 10.1128/CMR.00005-07

Meseko, C. A., Ehizibolo, D. O., Nwokike, E. C., and Wungak, Y. S. (2016). Serological evidence of equine influenza virus in horse stables in Kaduna, Nigeria. J. Equine Sci. 27, 99-105. doi: 10.1294/jes.27.99

Minke, J. M., Audonnet, J. C., and Fischer, L. (2004). Equine viral vaccines: the past, present and future. Vet. Res. 35, 425-443. doi: 10.1051/vetres:2004019

Minke, J. M., Toulemonde, C. E., Coupier, H., Guigal, P. M., Dinic, S., Sindle, T., et al. (2007). Efficacy of a canarypox-vectored recombinant vaccine expressing the hemagglutinin gene of equineinfluenza $\mathrm{H} 3 \mathrm{~N} 8$ virus in the protection of ponies from viral challenge. Am. J. Vet. Res. 68, 213-219. doi: 10.2460/ajvr.68.2.213

Moattari, A., Ashrafi, H., Kadivar, M. R., Kheiri, M. T., Shahidi, M., Arabpour, M., et al. (2010). Antigenic variations of human influenza virus in Shiraz, Iran. Indian J. Med. Microbiol. 28, 114-119. doi: 10.4103/0255-0857.62486

Morens, D. M., and Taubenberger, J. K. (2010). Historical thoughts on influenza viral ecosystems, or behold a pale horse, dead dogs, failing fowl, and sick swine. Influenza Other Respir. Viruses 4, 327-337. doi: 10.1111/j.1750-2659.2010.00148.x

Morley, P. S., Townsend, H. G., Bogdan, J. R., and Haines, D. M. (2000). Descriptive epidemiologic study of disease associated with influenza virus infections during three epidemics in horses. J. Am. Vet. Med. Assoc. 216, 535-544. doi: 10.2460/javma.2000.216.535

Mumford, J. A. (1990). The diagnosis and control of equine influenza, Proc. Am. Assoc. Equine Pract. 36:377.

Mumford, J. A., and Wood, J. (1993). Conference report on WHO/OIE meeting: consultation on newly emerging strains of equine influenza. Vaccine 11, 1172-1175. doi: 10.1016/0264-410X(93)90092-C

Murcia, P. R., Baillie, G. J., Daly, J., Elton, D., Jervis, C., Mumford, J. A., et al. (2010). Intra- and interhost evolutionary dynamics of equine influenza virus. J. Virol. 84, 6943-6954. doi: 10.1128/JVI.00112-10

Murcia, P. R., Baillie, G. J., Stack, J. C., Jervis, C., Elton, D., Mumford, J. A., et al. (2013). Evolution of equine influenza virus in vaccinated horses. J. Virol. 87, 4768-4771. doi: 10.1128/JVI.03379-12

Na, W., Kang, B., Kim, H. I., Hong, M., Park, S. J., Jeoung, H. Y., et al. (2014). Isolation and genetic characterization of naturally NS-truncated H3N8 equine influenza virus in South Korea. Epidemiol. Infect. 142, 759-766. doi: 10.1017/S095026881300143X

Na, W., Yeom, M., Yuk, H., Moon, H., Kang, B., and Song, D. (2016). Influenza virus vaccine for neglected hosts: horses and dogs. Clin. Exp. Vaccine Res. 5, 117-124. doi: 10.7774/cevr.2016.5.2.117

Nedland, H., Wollman, J., Sreenivasan, C., Quast, M., Singrey, A., Fawcett, L., et al. (2018). Serological evidence for the co-circulation of two lineages of influenza $\mathrm{D}$ viruses in equine populations of the Midwest United States. Zoonoses Public Health 65, e148-e154. doi: 10.1111/zph.12423

Nelson, K. M., Schram, B. R., and McGregor, M. W. (1998). Local and systemic isotype-specific antibody responses to equine influenza virus infection versus conventional vaccination. Vaccine 16, 1306-1313. doi: 10.1016/S0264-410X(98)00009-7

Nemoto, M., Yamanaka, T., Bannai, H., Tsujimura, K., and Kokado, H. (2018). Complete genomic sequences of H3N8 equine influenza virus strains used as vaccine strains in Japan. Genome Announc. 6, e00172-e00118. doi: 10.1128/genomeA.00172-18

Nemoto, M., Yamanaka, T., Bannai, H., Tsujimura, K., Kondo, T., and Matsumura, T. (2011). Development and evaluation of a reverse transcription loopmediated isothermal amplification assay for $\mathrm{H} 3 \mathrm{~N} 8$ equine influenza virus. J. Virol. Methods 178, 239-242. doi: 10.1016/j.jviromet.2011. 07.015

Nemoto, M., Yamanaka, T., Bannai, H., Tsujimura, K., Kondo, T., and Matsumura, T. (2012). Development of a reverse transcription loop-mediated isothermal amplification assay for H7N7 equine influenza virus. J. Vet. Med. Sci. 74, 929-931. doi: 10.1292/jvms.11-0541

Newton, J. R., and Mumford, J. A. (2005). “Equine influenza," in Infectious Diseases of Livestock, Vol. 1, ed J. A. W. Coetzer and R. C. Tustin (Oxford: Oxford University Press), 766-774.

Newton, R., Cooke, A., Elton, D., Bryant, N., Rash, A., Bowman, S., et al. (2007). Canine influenza virus: cross-species transmission from horses. Vet. Rec. 161, 142-143. doi: 10.1136/vr.161.4.142-a

Nogales, A., and Martínez-Sobrido, L. (2017). Reverse genetics approaches for the development of influenza vaccines. Int. J. Mol. Sci. 18:20. doi: 10.3390/ijms18010020.

NRCE Annual Report (2010). National Research Central on Equines, Annual Report 2009-2010. 21 pp. Available online at: http://nrce.gov.in/downloads/NRCE \%20Annual\%20Report\%202009-10.pdf

OIE (2008). Equine Influenza. Manual of Diagnostic Tests and Vaccines for Terrestrial Animals. Chapter 2.5.7 (Paris: Office International Des Epizooties), 871-883. 
Oishi, K., Yamayoshi, S., and Kawaoka, Y. (2018). Identification of novel amino acid residues of influenza virus PA-X that are important for PA-X shut off activity by using yeast. Virology 516, 71-75. doi: 10.1016/j.virol.2018.01.004

Olsen, C. W. (2000). DNA vaccination against influenza viruses: a review with emphasis on equine and swine influenza. Vet. Microbiol. 74, 149-164. doi: 10.1016/S0378-1135(00)00175-9

Oxburgh, L., and Hagström, A. (1999). A PCR based method for the identification of equine influenza virus from clinical samples. Vet. Microbiol. 67, 161-174. doi: 10.1016/S0378-1135(99)00041-3

Oxburgh, L., and Klingeborn, B. (1999). Cocirculation of two distinct lineages of equine influenza virus subtype H3N8. J. Clin. Microbiol. 37, 3005-3009.

Ozaki, H., Sugita, S., and Kida, H. (2000). A rapid and sensitive method for diagnosis of equine influenza by antigen detection using immuno-PCR. Jap. J. Vet. Res. 48, 187-195.

Paillot, R. (2014). A systematic review of recent advances in equine influenza vaccination. Vaccines 2, 797-831. doi: 10.3390/vaccines2040797

Paillot, R., and El-Hage, C. M. (2016). The use of a recombinant canary pox-based equine influenza vaccine during the 2007 Australian outbreak: a systematic review and summary. Pathogens 5:42. doi: 10.3390/pathogens5020042

Paillot, R., Grimmett, H., Elton, D., Daly, J. M. (2008). Protection, systemic IFN $\gamma$, and antibody responses induced by an ISCOM-based vaccine against a recent equine influenza virus in its natural host. Vet. Res. 39:1. doi: 10.1051/vetres:2007062

Paillot, R., Hannant, D., Kydd, J. H., Daly, J. M. (2006b). Vaccination against equine influenza: quid novi? Vaccine 24, 4047-4061. doi: 10.1016/j.vaccine.2006.02.030

Paillot, R., Kydd, J. H., Sindle, T., Hannant, D., Edlund Toulemonde, C., Audonnet, J. C., et al. (2006a). Antibody and IFN-gamma responses induced by a recombinant canarypox vaccine and challenge infection with equine influenza virus. Vet. Immunol. Immunopathol. 112, 225-233. doi: 10.1016/j.vetimm.2006.02.007

Paillot, R., Lemaitre, L., Dancer, A., Thibault, J.-C., and Minke, J. (2014), Development and efficacy of the recombinant canarypox-based equine influenza (EI) vaccine updated according to the last OIE expert surveillance panel recommendations. Equine Vet. J. 46:14. doi: 10.1111/evj.12323_29

Paillot, R., Marcillaud Pitel, C., D’Ablon, X., and Pronost, S. (2017). Equine vaccines: How, when and why? Report of the vaccinology session, French Equine Veterinarians Association, 2016. Reims. Vaccines 5, 1-11. doi: 10.3390/vaccines5040046

Paillot, R., and Prowse, L. (2012). ISCOM-matrix-based equine influenza (EIV) vaccine stimulates cell-mediated immunity in the horse. Vet. Immunol. Immunopathol. 145, 516-521. doi: 10.1016/j.vetimm.2011.11.019

Paillot, R., Prowse, L., Donald, C., Medcalf, E., Montesso, F., Bryant, N., et al. (2010). Efficacy of a whole inactivated EI vaccine against a recent EIV outbreak isolate and comparative detection of virus shedding. Vet. Immunol. Immunopathol. 136, 272-83. doi: 10.1016/j.vetimm.2010.03.019

Paillot, R., Prowse, L., Montesso, F., Huang, C. M., Barnes, H., Escala, J. (2013a) Whole inactivated equine influenza vaccine: efficacy against a representative clade 2 equine influenza virus, IFNgamma synthesis and duration of humoral immunity. Vet. Microbiol. 162, 396-407. doi: 10.1016/j.vetmic.2012.10.019

Paillot, R., Prowse, L., Montesso, F., Stewart, B., Jordon, L., Newton, J. R., et al. (2013b). Duration of equine influenza virus shedding and infectivity in immunised horses after experimental infection with EIV A/eq2/Richmond/1/07. Vet. Microbiol. 166, 22-34. doi: 10.1016/j.vetmic.2013.04.027

Park, A. W., Daly, J. M., Lewis, N. S., Smith, D. J., Wood, J. L. N., and Grenfell, B. T. (2009). Quantifying the impact of immune escape on transmission dynamics of influenza. Science 326, 726-728. doi: 10.1126/science.1175980

Park, A. W., Wood, J. L. N., Newton, J. R., Daly, J., Mumford, J. A., and Grenfell, B. T. (2003). Optimizing vaccination strategies in equine influenza. Vaccine 21, 2862-2870. doi: 10.1016/S0264-410X(03)00156-7

Parrish, C. R., Murcia, P. R., and Holmes, E. C. (2015). Influenza virus reservoirs and intermediate hosts: dogs, horses, and new possibilities for influenza virus exposure of humans. J. Virol. 89, 2990-2994. doi: 10.1128/JVI.03146-14

Paterson, D., and Fodor, E. (2012). Emerging roles for the influenza A virus nuclear export protein (NEP). PLoS Pathog. 8:e1003019. doi: 10.1371/journal.ppat.1003019

Patterson-Kane, J. C., Carrick, J. B., Axon, J. E., Wilkie, I., and Beegg, A. P. (2008). Thee pathology of bronchointerstitial pneumonia in young foals associated with the first outbreak of equine influenza in Australia. Equine Vet. J. 40, 199-203. doi: 10.2746/042516408X292214

Pavulraj, S., Bera, B. C., Joshi, A., Anand, T., Virmani, M., Vaid, R. K., et al. (2015). Pathology of equine influenza virus (H3N8) in murine model. PLoS ONE 10:e0143094. doi: 10.1371/journal.pone.0143094

Pavulraj, S., Virmani, N., Bera, B. C., Joshi, A., Anand, T., Virmani, M., et al. (2017). Immunogenicity and protective efficacy of inactivated equine influenza (H3N8) virus vaccine in murine model. Vet. Microbiol. 210, 188-196. doi: 10.1016/j.vetmic.2017.08.013

Pecoraro, H. L., Bennett, S., Garretson, K., Quintana, A. M., Lunn, K. F., Landolt, G. A. (2013). Comparison of the infectivity and transmission of contemporary canine and equine H3N8 influenza viruses in dogs. Vet. Med. Int. 2013: 874521. doi: $10.1155 / 2013 / 874521$

Perglione, C. O., Golemba, M. D., Torres, C., and Barrandeguy, M. (2016). Molecular epidemiology and spatio-temporal dynamics of the H3N8 equine influenza virus in South America. Pathogens 5:61. doi: 10.3390/pathogens5040061

Perkins, N. R., Webster, W. R., Wright, T., Denney, I., and Links, I. (2011). Vaccination program in the response to the 2007 equine influenza outbreak in Australia. Aust. Vet. J. 89, 126-134. doi: 10.1111/j.1751-0813.2011.00766.x

Prasad, M., Lambe, U. P., Brar, B., Shah, I., Manimegalai, J., Ranjan, K., et al. (2018). Nanotherapeutics: an insight into healthcare and multi-dimensional applications in medical sector of the modern world. Biomed. Pharmacother. 97, 1521-1537. doi: 10.1016/j.biopha.2017.11.026

Purzycka, M., Rozek, W., and Zmudzinski, J. F. (2004). Global distribution of equine influenza. Med. Weter. 60, 675-679.

Qi, T., Guo, W., Huang, W. Q., Li, H. M., Zhao, L. P., Dai, L. L., et al. (2010). Genetic evolution of equine influenza viruses isolated in China. Arch. Virol. 155, 1425-1432. doi: 10.1007/s00705-010-0724-y

Quinlivan, M., Zamarin, D., García-Sastre, A., Cullinane, A., Chambers, T., and Palese, P. (2005). Attenuation of equine influenza viruses through truncations of the NS1 protein. J. Virol. 79, 8431-8439. doi: 10.1128/JVI.79.13.8431-8439.2005

Radostits, O. M., Gay, C. C., Blood, D. C., and Hinchcliff, K. W. (2003). "Equine influenza," in Veterinary Medicine, A Text Book of Diseases of Cattle, Sheep, Pigs, Goats and Horses, 9th Edn (New York, NY: Elsevier Saunders), 1144-1147.

Rash, A., Morton, R., Woodward, A., Maes, O., McCauley, J., Bryant, N., et al. (2017). Evolution and divergence of H3N8 equine influenza viruses circulating in the United Kingdom from 2013 to 2015. Pathogens 6:6. doi: 10.3390/pathogens6010006.

Read, A. J., Arzey, K. E., Finlaison, D. S., Gu, X., Davis, R. J., Ritchie, L., et al. (2012). A prospective longitudinal study of naturally infected horses to evaluate the performance characteristics of rapid diagnostic tests for equine influenza virus. Vet. Microbiol. 156, 246-255. doi: 10.1016/j.vetmic.2011.10.031

Rivailler, P., Perry, I. A., Jang, Y., Davis, C. T., Chen, L. M., Dubovi, E. J., et al. (2010). Evolution of canine and equine influenza (H3N8) viruses co-circulating between 2005 and 2008. Virology 408, 71-79. doi: 10.1016/j.virol.2010. 08.022

Rodriguez, L., Reedy, S., Nogales, A., Murcia, P. R., Chambers, T. M., and Martinez-Sobrido, L. (2018). Development of a novel equine influenza virus live-attenuated vaccine. Virology 516, 76-85. doi: 10.1016/j.virol.2018.01.005

Rosanowski, S. M., Cogger, N., Rogers, C. W., Stevenson, M. A. (2016). Evaluating the effectiveness of strategies for the control of equine influenza virus in the New Zealand equine population. Transbound Emerg. Dis. 63, 321-332. doi: 10.1111/tbed.12277

Rozek, W., Kwasnik, M., and Zmudzinski, J. F. (2011). Detection of antibodies against equine influenza virus by cell based enzyme-linked immunosorbent assay. Bull. Vet. Inst. Pulawy 55, 569-574.

Sack, A., Daramragchaa, U., Chuluunbaatar, M., Gonchigoo, B., Bazartseren, B., Tsogbadrakh, N., et al. (2017). Low prevalence of enzootic equine influenza virus among horses in Mongolia. Pathogens 6:61. doi: 10.3390/pathogens6040061

Sajid, M., Ahmad, M. U., Khan, M. A., Anjum, M. A., and Mushtaq, M. H. (2013). Investigation of equine influenza virus in two geographical regions of Pakistan. Trop. Anim. Health Prod. 45, 693-694. doi: 10.1007/s11250-012-0247-5

Schemann, K., Firestone, S. M., Taylor, M. R., Toribio, J. A., Ward, M. P., and Dhand, N. K. (2012). Horse owners'/managers' perceptions about effectiveness of biosecurity measures based on their experiences during the 
2007 equine influenza outbreak in Australia. Prev. Vet. Med. 106, 97-107. doi: 10.1016/j.prevetmed.2012.01.013

Scocco, P., and Pedini, V. (2008). Localization of influenza virus sialoreceptors in equine respiratory tract. Histol. Histopathol. 23, 973-978. doi: $10.14670 / \mathrm{HH}-23.973$

Shi, W., Lei, F., Zhu, C., Sievers, F., and Higgins, D. G. (2010). A complete analysis of HA and NA genes of influenza A viruses. PLoS ONE 5:e14454. doi: 10.1371/journal.pone.0014454

Short, K. R., Richard, M., Verhagen, J. H., van Riel, D., Schrauwen, E. J., van den Brand, J. M., et al. (2015). One health, multiple challenges: The inter-species transmission of influenza A virus. One Health 1, 1-13. doi: 10.1016/j.onehlt.2015.03.001

Slater, J., and Hannant, D. (2000). Equine immunity to viruses. Vet. Clin. N. Am. Equine Pract. 16, 49-68. doi: 10.1016/S0749-0739(17)30118-9

Smyth, B. (2007). Equine influenza: an update. Aust. Vet. J. 85, 14 \& 16.

Soboll, G., Horohov, D. W., Aldridge, B. M., Olsen, C. W., McGregor, M. W., Drape, R. J., et al. (2003). Regional antibody and cellular immune responses to equine influenza virus infection, and particle mediated DNA vaccination. Vet. Immunol. Immunopathol. 94, 47-62. doi: 10.1016/S0165-2427(03)00 060-6

Soboll, G., Hussey, S. B., Minke, J. M., Landolt, G. A., Hunter, J. S., Jagannatha, S., et al. (2010). Onset and duration of immunity to equine influenza virus resulting from canarypox-vectored (ALVAC) vaccination. Vet. Immunol. Immunopathol. 135, 100-107. doi: 10.1016/j.vetimm.2009.11.007

Solórzano, A., Foni, E., Córdoba, L., Baratelli, M., Razzuoli, E., Bilato, D., et al. (2015). Cross-species infectivity of H3N8 influenza virus in an experimental infection in swine. J. Virol. 89, 11190-11202. doi: 10.1128/JVI.01509-15

Sovinova, O., Tumova, B., Pouska, F., and Nemec, J. (1958). Isolation of a virus causing respiratory disease in horses. Acta Virol. 2, 51-61.

Sreenivasan, C. C., Jandhyala, S. S., Luo, S., Hause, B. M., Thomas, M., Knudsen, D. E. B., et al. (2018). Phylogenetic analysis and characterization of a sporadic isolate of equine influenza A H3N8 from an unvaccinated horse in 2015. Viruses 10:E31. doi: 10.3390/v10010031

Stack, J. C., Murcia, P. R., Grenfell, B. T., Wood, J. L., Holmes, E. C. (2013). Inferring the inter-host transmission of influenza A virus using patterns of intrahost genetic variation. Proc. Biol. Sci. 280:20122173. doi: $10.1098 /$ rspb.2012.2173

Su, S., Wang, L., Fu, X., He, S., Hong, M., Zhou, P., et al. (2014). Equine influenza A(H3N8) virus infection in cats. Emerg. Infect. Dis. 20, 2096-2099. doi: $10.3201 /$ eid2012.140867

Suzuki, Y. (2000). Receptor sialylsugar chains as determinants of host range of influenza viruses. Nippon Rinsho 58, 2206-2210.

Sylte, M. J., and Suarez, D. L. (2009). "Influenza neuraminidase as a vaccine antigen," in Vaccines for Pandemic Influenza. Current Topics in Microbiology and Immunology, Vol. 333, ed R. Compans and W. Orenstein (Berlin; Heidelberg: Springer).

Tabynov, K., Kydyrbayev, Z., Ryskeldinova, S., Assanzhanova, N., Kozhamkulov, Y., Inkarbekov, D., et al. (2014). Safety and immunogenicity of a novel coldadapted modified-live equine influenza virus vaccine. Aust. Vet. J. 92, 450-457. doi: $10.1111 /$ avj.12248

Takahashi, T., Unuma, S., Kawagishi, S., Kurebayashi, Y., Takano, M., Yoshino, H., et al. (2016). Substrate specificity of equine and human influenza A virus sialidase to molecular species of sialic acid. Biol. Pharm. Bull. 39, 1728-1733. doi: 10.1248/bpb.b16-00345

Timoney, P. J. (1996). Equine influenza. Comp. Immunol. Microbiol. Infect. Dis. 19, 205-211. doi: 10.1016/0147-9571(96)00006-9

Townsend, H. G., Penner, S. J., Watts, T. C., Cook, A., Bogdan, J., Haines, D. M., et al. (2001). Efficacy of a cold-adapted, intranasal, equine influenza vaccinechallenge trials. Equine Vet. J. 33, 637-643. doi: 10.2746/0425164017762 49354

Townsend, H. G. G., Cook, A., and Watts, T. C. (1999). Efficacy of a cold-adapted, modified-live virus influenza vaccine: a double-blind challenge trial. Proc. Am. Assoc. Equine Pract. 45, 41-42.

Tu, J., Zhou, H., Jiang, T., Li, C., Zhang, A., Guo, X., et al. (2009). Isolation and molecular characterization of equine $\mathrm{H} 3 \mathrm{~N} 8$ influenza viruses from pigs in China. Arch. Virol. 154, 887-890. doi: 10.1007/s00705-009-0381-1

Uppal, P. K., and Yadav, M. P. (1987). Outbreak of equine influenza in India. Vet. Rec. 121, 569-570.
Uppal, P. K., Yadav, M. P., and Oberoi, M. S. (1989). Isolation of A/Equi-2 virus during 1987 equine influenza epidemic in India. Equine Vet. J. 21, 364-366. doi: 10.1111/j.2042-3306.1989.tb02690.x

Uppal, P. K., Yadav, M. P., and Sharma, S. N. (1987). Occurrence of equine influenza outbreaks in India. Indian J. Comp. Microbiol. Immunol. Infect. Dis. 8, 91-94.

Van de Walle, G. R., May, M. A., Peters, S. T., Metzger, S. M., Rosas, C. T., and Osterrieder, N. (2010). A vectored equine herpesvirus type 1 (EHV-1) vaccine elicits protective immune responses against EHV-1 and H3N8 equine influenza virus. Vaccine 28, 1048-1055. doi: 10.1016/j.vaccine.2009.10.123

van Maanen, C., and Cullinane, A. (2002). Equine influenza virus infections: an update. Vet. Quart. 24, 79-94. doi: 10.1080/01652176.2002.9695127

Virmani, N., Bera, B. C., Gulati, B. R., Karuppusamy, S., Singh, B. K., Kumar Vaid, R., et al. (2010a). Descriptive epidemiology of equine influenza in India (2008-2009): temporal and spatial trends. Vet. Ital. 46, 449-458.

Virmani, N., Bera, B. C., Shanumugasundaram, K., Singh, B. K., Gulati, B. R., Singh, R. K., et al. (2011). Genetic analysis of the matrix and non-structural genes of equine influenza virus (H3N8) from epizootic of 2008-2009 in India. Vet. Microbiol. 152, 169-175. doi: 10.1016/j.vetmic.2011.04.011

Virmani, N., Bera, B. C., Singh, B. K., Shanmugasundaram, K., Gulati, B. R., Barua, S., et al. (2010b). Equine influenza outbreak in India (2008-09): virus isolation, sero-epidemiology and phylogenetic analysis of HA gene. Vet. Microbiol. 143, 224-237 doi: 10.1016/j.vetmic.2009.12.007

Virmani, N., Singh, B. K., Gulati, B. R., and Kumar, S. (2008). Equine influenza outbreak in India. Vet. Rec. 163, 607-608. doi: 10.1136/vr.163.20.607-a

Waddel, G. H., Teigland, M. B., and Sigel, M. M. (1963). A new influenza virus associated with equine respiratory disease. J. Am. Vet. Med. Assoc. 143, 587-590.

Wang, C., Wang, Q., Hu, J., Sun, H., Pu, J., Liu, J. et al. (2017). A multiplex RT-PCR assay for detection and differentiation of avian-origin canine $\mathrm{H} 3 \mathrm{~N} 2$, equineorigin $\mathrm{H} 3 \mathrm{~N} 8$, human-origin $\mathrm{H} 3 \mathrm{~N} 2$, and $\mathrm{H} 1 \mathrm{~N} 1 / 2009$ canine influenza viruses. PLoS ONE 12:e0170374. doi: 10.1371/journal.pone.0170374

Watson, J., Daniels, P., Kirkland, P., Carroll, A., Jeggo, M. (2011). The 2007 outbreak of equine influenza in Australia: lessons learned for international trade in horses. Rev. Sci. Tech. 30, 87-93. doi: 10.20506/rst.30.1.2021

Webby, R. J., Webster, R. G., and Richt, J. A. (2007). Influenza viruses in animal wildlife populations. Curr. Top. Microbiol. Immunol. 315, 67-83. doi: 10.1007/978-3-540-70962-6_4

Webster, R. G. (1993). Are equine 1 influenza viruses still present in horses? Equine Vet. J. 25, 537-538. doi: 10.1111/j.2042-3306.1993.tb03009.x

Whitlock, F., Rash, A., and Elton, D. (2018). Equine influenza: evolution of a highly infectious virus. Vet. Rec. 182, 710-711. doi: 10.1136/vr.k2727

Wilson, W. D. (1993). Equine influenza. Vet. Clin. N. Am. Equine Pract. 9, 257-282. doi: 10.1016/S0749-0739(17)30395-4

Wise, H. M., Foeglein, A., Sun, J., Dalton, R. M., Patel, S., Howard, W., et al. (2009). A complicated message: identification of a novel PB1-related protein translated from influenza A virus segment 2 mRNA. J. Virol. 83, 8021-8031. doi: 10.1128/JVI.00826-09

Wood, J., and Mumford, J. (1992). Epidemiology of equine influenza. Vet. Rec. 130:126. doi: 10.1136/vr.130.6.126-c

Wood, J. M., Schild, G. C., Folkers, C., Mumford, J., and Newman, R. W. (1983). The standardisation of inactivated equine influenza vaccines by single-radial immunodiffusion. J. Biol. Standard. 11, 133-136. doi: 10.1016/S0092-1157(83)80037-7

Woodward, A., Rash, A. S., Medcalf, E., Bryant, N. A., and Elton, D. M. (2015). Using epidemics to map $\mathrm{H} 3$ equine influenza virus determinants of antigenicity. Virology 481, 187-198. doi: 10.1016/j.virol.2015.02.027

Woodward, A. L., Rash, A. S., Blinman, D., Bowman, S., Chambers. T. M., Daly, J. M., et al. (2014). Development of a surveillance scheme for equine influenza in the UK and characterisation of viruses isolated in Europe, Dubai and the USA from 2010-2012. Vet. Microbiol. 169, 113-127. doi: 10.1016/j.vetmic.2013.11.039

Xie, T., Anderson, B. D., Daramragchaa, U., Chuluunbaatar, M., and Gray, G. C. (2016). A review of evidence that equine influenza viruses are zoonotic. Pathogens 5:50. doi: 10.3390/pathogens5030050

Yamanaka, T., Bannai, H., Nemoto, M., Tsujimura, K., Kondo, T., Muranaka, M., et al. (2012b). Efficacy of a single intravenous dose of the neuraminidase inhibitor peramivir in the treatment of equine influenza. Vet. J. 193, 358-362. doi: 10.1016/j.tvjl.2012.01.005 
Yamanaka, T., Cullinane, A., Gildea, S., Bannai, H., Nemoto, M., Tsujimura, K., et al. (2015). The potential impact of a single amino-acid substitution on the efficacy of equine influenza vaccines. Equine Vet. J. 47, 456-462. doi: $10.1111 /$ evj.12290

Yamanaka, T., Nemoto, M., Bannai, H., Tsujimura, K., Kondo, T., Matsumura, T., et al. (2012a). No evidence of horizontal infection in horses kept in close contact with dogs experimentally infected with canine influenza A virus (H3N8). Acta Vet. Scand. 54:25. doi: 10.1186/1751-0147-54-25

Yamanaka, T., Nemoto, M., Bannai, H., Tsujimura, K., Kondo, T., Matsumura, T., et al. (2016a). Evaluation of twenty-two rapid antigen detection tests in the diagnosis of equine influenza caused by viruses of $\mathrm{H} 3 \mathrm{~N} 8$ subtype. Influenza Other Respir. Viruses 10, 127-133. doi: 10.1111/irv. 12358

Yamanaka, T., Nemoto, M., Bannai, H., Tsujimura, K., Kondo, T., Matsumura, T., et al. (2016b). Assessment of antigenic difference of equine influenza virus strains by challenge study in horses. Influenza Other Respir. Viruses 10, 536-539. doi: $10.1111 /$ irv. 12418

Yamanaka, T., Nemoto, M., Bannai, H., Tsujimura, K., Kondo, T., Matsumura, T., et al. (2017a). Rapid diagnosis of equine influenza by highly sensitive silver amplification immunochromatography system. J. Vet. Med. Sci. 79, 1061-1063. doi: $10.1292 /$ jvms.17-0105

Yamanaka, T., Nemoto, M., Bannai, H., Tsujimura, K., Matsumura, T., Kokado, H., et al. (2017b). Neutralization antibody response to booster/priming immunization with new equine influenza vaccine in Japan. J. Vet. Med. Sci. 80, 382-386. doi: 10.1292/jvms.17-0538

Yamanaka, T., Nemoto, M., Tsujimura, K., Kondo, T., and Matsumura, T. (2009). Interspecies transmission of equine influenza virus (H3N8) to dogs by close contact with experimentally infected horses. Vet. Microbiol. 139, 351-355. doi: 10.1016/j.vetmic.2009. 06.015

Yamanaka, T., Niwa, H., Tsujimura, K., Kondo, T., and Matsumura, T. (2008a). Epidemic of equine influenza among vaccinated racehorses in Japan in 2007. J. Vet. Med. Sci. 70, 623-625. doi: 10.1292/jvms. 70.623

Yamanaka, T., Tsujimura, K., Kondo, T., and Matsumura, T. (2008b). Evaluation of antigen detection kits for diagnosis of equine influenza. J. Vet. Med. Sci. 70, 189-192. doi: 10.1292/jvms.70.189
Yamanaka, T., Tsujimura, K., Kondo, T., Matsumura, T., Ishida, H., Kiso, M., et al. (2010). Infectivity and pathogenicity of canine H3N8 influenza A virus in horses. Influenza Other Respir. Viruses 4, 345-351. doi: 10.1111/j.1750-2659.2010.00157.x

Yang, H., Xiao, Y., Meng, F., Sun, F., Chen, M., Cheng, Z., et al. (2018). Emergence of H3N8 equine influenza virus in donkeys in China in 2017. Vet. Microbiol. 214, 1-6. doi: 10.1016/j.vetmic.2017.11.033

Yates, P., and Mumford, J. A. (2000). Equine influenza vaccine efficacy: the significance of antigenic variation. Vet. Microbiol. 74, 173-177. doi: $10.1016 / \mathrm{S} 0378-1135(00) 00177-2$

Ye, J., Xu, Y., Harris, J., Sun, H., Bowman, A. S., Cunningham, F., et al. (2013). Mutation from arginine to lysine at the position 189 of hemagglutinin contributes to the antigenic drift in H3N2 swine influenza viruses. Virology 446 , 225-229. doi: 10.1016/j.virol.2013.08.004

Yin, X., Lu, G., Guo, W., Qi, T., Ma, J., Zhu, C., et al. (2014). Identification of equine influenza virus infection in Asian wild horses (Equus przewalskii). Arch. Virol. 159, 1159-1162. doi: 10.1007/s00705-013-1908-z

Yondon, M., Heil, G. L., Burks, J. P., Zayat, B., Waltzek, T. B., Jamiyan, B. O. et al. (2013). Isolation and characterization of H3N8 equine influenza A virus associated with the 2011 epizootic in Mongolia. Influenza Other Respir. Viruses 7, 659-665. doi: 10.1111/irv.12069

Yondon, M., Zayat, B., Nelson, M. I., Heil, G. L., Anderson, B. D., Lin, X., et al. (2014). Equine influenza A (H3N8) virus isolated from Bactrian camel, Mongolia. Emerg. Infect. Dis. 20, 2144-2147. doi: 10.3201/eid2012.140435

Conflict of Interest Statement: The authors declare that the research was conducted in the absence of any commercial or financial relationships that could be construed as a potential conflict of interest.

Copyright (c) 2018 Singh, Dhama, Karthik, Khandia, Munjal, Khurana, Chakraborty, Malik, Virmani, Singh, Tripathi, Munir and van der Kolk. This is an open-access article distributed under the terms of the Creative Commons Attribution License (CC BY). The use, distribution or reproduction in other forums is permitted, provided the original author(s) and the copyright owner(s) are credited and that the original publication in this journal is cited, in accordance with accepted academic practice. No use, distribution or reproduction is permitted which does not comply with these terms. 